\title{
Structure and Conversion Kinetics of a Bi-stable DNA i-motif: Broken Symmetry in the $[\mathrm{d}(5 \mathrm{mCCTCC})] 4$ Tetramer
}

\section{Sylvie Nonin and Jean-Louis Leroy*}

Groupe de Biophysique de l'Ecole Polytechnique et de 1'URA D1254 du CNRS 91128 Palaiseau, France

*Corresponding author

\begin{abstract}
At slightly acidic $\mathrm{pH}$, protonation of C-rich oligomers results in the formation of a four-stranded structure composed of two parallel duplexes in a head to tail orientation with their hemi-protonated $\mathrm{C} \cdot \mathrm{C}^{+}$pairs intercalated in a so-called i-motif. In all cases reported previously the duplexes are identical.

The tetramer formed by the $\mathrm{d}(5 \mathrm{mCCTCC})$ oligomer is different. The structure is computed on the basis of 55 inter-residue distances derived from NOESY cross-peaks measured at short mixing times. It consists of two intercalated non-equivalent symmetrical duplexes. The base stacking order is $\mathrm{C}^{*} \mathrm{C} 1 \mathrm{C} 4 * \mathrm{C} 2(\mathrm{~T} 3 *) \mathrm{T} 3 \mathrm{C} 2 * \mathrm{C} 4 \mathrm{C} 1 * \mathrm{C} 5$, but the thymidine bases $\left(\mathrm{T} 3^{*}\right)$ of one duplex are looped out and lie in the wide grooves of the tetramer. The thymidine bases $\mathrm{T} 3$ stack as a symmetrical T.T pair between the sequentially adjacent $\mathrm{C} 2 \cdot \mathrm{C} 2^{+}$pair and the $\mathrm{C} 2 * \cdot \mathrm{C} 2^{*+}$ pair of the other duplex.

Numerous exchange cross-peaks provide evidence for duplex interconversion. The interconversion rate is $1.4 \mathrm{~s}^{-1}$ at $0^{\circ} \mathrm{C}$ and the activation energy is $94 \mathrm{~kJ} / \mathrm{mol}$.

The opening of the T3.T3 pair, the closing of the T3*T3 pair, and the opening of the $\mathrm{C} 2 * \mathrm{C} 2{ }^{*+}$ pair occur simultaneously with the duplex interconversion. This suggests that the concerted opening and closing of the thymidine bases drive the duplex interconversion. Opening of the $\mathrm{C} 4 \cdot \mathrm{C}^{+}{ }^{+}$and $\mathrm{C} 4 * \cdot \mathrm{C} 4{ }^{*+}$ pairs, and dissociation of the tetramer are not part of the interconversion since they occur at much slower rates. Duplex interconversion within the $[\mathrm{d}(5 \mathrm{mCCTCC})] 4$ tetramer provides the first structural and kinetics characterization of broken symmetry in a biopolymer.

The tetramer formed by $\mathrm{d}(5 \mathrm{mCCUCC})$ adopts a similar structure, but the rate of duplex interconversion is faster: $40 \mathrm{~s}^{-1}$ at $0^{\circ} \mathrm{C}$. At $32^{\circ} \mathrm{C}$, interconversion is fast on the NMR time scale.
\end{abstract}

Keywords: i-motif; proton exchange; DNA solution structure; telomer; tetramer

\section{Introduction}

Parallel duplexes of cytidine-rich oligomers held together by hemi-protonated $\mathrm{C} \cdot \mathrm{C}^{+}$pairs were

Abbreviations used: 1D, one-dimensional; 2D, two-dimensional; $5 \mathrm{mC}$, 5-methylcytidine; $\mathrm{H}_{\text {ext }}$, cytidine external amino proton; $\mathrm{H} 4_{\text {int }}$, cytidine internal (H-bonded) amino proton; JR, jump-and-return; NMR, nuclear magnetic resonance; NOE, nuclear Overhauser effect; NOESY, nuclear Overhauser effect spectroscopy; RMSD, root mean square deviation; TOCSY, total correlation spectroscopy; ppm, parts per million. described more than 30 years ago (Langridge \& Rich, 1963; Inman, 1964). Recently, NMR experiments established that two parallel deoxy-oligocytidine duplexes associate head-to-tail to form a four-stranded structure with $\mathrm{C} \cdot \mathrm{C}^{+}$pairs intercalated face-to-face in a so called i-motif (Gehring et al., 1993).

The i-motif structure can be formed by four strands carrying one oligo $(\mathrm{dC})$ stretch each (Gehring et al., 1993; Chen et al., 1994; Kang et al., 1994, 1995; Leroy \& Guéron, 1995; Berger et al., 1995), by two strands carrying two oligo(dC) stretches each (Rohozinski et al., 1994), or by one 
strand carrying four oligo(C) stretches (Leroy et al., 1994; Mergny et al., 1995).

The formation of a C.C $\mathrm{C}^{+}$pair shifts the protonation equilibrium of the cytidine $\mathrm{N} 3$ nitrogen $\left(\mathrm{p} K_{\mathrm{N} 3}=4.3\right)$. It is of particular interest that the telomeric oligo $(\mathrm{C})$ repeat of vertebrates folds into an i-motif at pH 7 (Leroy et al., 1994).

High definition structures of the i-motif were obtained recently for the tetramers of $\mathrm{d}(\mathrm{TCC})$ and $\mathrm{d}(5 \mathrm{mCCT})$, and it was shown that the i-motif intercalation topology may be derived directly from characteristic features of the NOESY spectrum, namely the inter-residue connectivities of the $\mathrm{H} 1^{\prime}-\mathrm{H} 1^{\prime}$ protons and the cross-peaks between amino protons and $\mathrm{H} 2{ }^{\prime} / \mathrm{H} 2 "$ protons (Leroy \& Guéron, 1995).

Here, we use these determinants to solve the structure formed by d(CCTCC), a sequence chosen to determine how the i-motif may incorporate a $\mathrm{T} \cdot \mathrm{T}$ pair, and by the related sequence $\mathrm{d}(5 \mathrm{mCCTCC})$. The stoichiometry, the stability, and the NMR characteristics of both multimers are similar but the larger dispersion of the amino proton chemical shifts favours the methylated sequence for the structural study.

Gel filtration experiments demonstrate the tetrameric stoichiometry of the structure formed by the $\mathrm{d}(5 \mathrm{mCCTCC})$ oligomer and the connectivities of the NOESY spectra are characteristic of the i-motif. The presence of two spin systems per residue indicates a non-symmetrical structure, which differs from the fully symmetrical ones reported in all previous solution studies.

The structure computed on the basis of the distance restraints corresponding to NOESY crosspeaks measured at short mixing times is a tetramer formed by intercalation of two different symmetrical duplexes. NOESY spectra recorded at high temperature reveal an interconversion process between both duplexes which we further characterize by kinetics experiments involving gel filtration chromatography, saturation transfer and proton exchange. Finally, we compare the interconversion kinetics of $[\mathrm{d}(5 \mathrm{mCCTCC})] 4$ and of its uridine homologue $[\mathrm{d}(5 \mathrm{mCCUCC})] 4$.

\section{Results}

\section{Stoichiometry, stability and dissociation kinetics of the multimer}

The elution profile of the d(CCTCC) oligomer on a gel filtration column shows two components in proportions dependent on the oligomer concentration. Using a calibrated column, we ascribed one component to the monomer $(6( \pm 2)$ nucleosides) and the other to a multimer of $17( \pm 4)$ nucleosides.

Samples of $\mathrm{d}(\mathrm{CCTCC})$ at different concentrations were prepared by successive dilutions of a concentrated sample. Gel filtration profiles obtained after waiting different time intervals showed very slow dissociation kinetics of the multimer

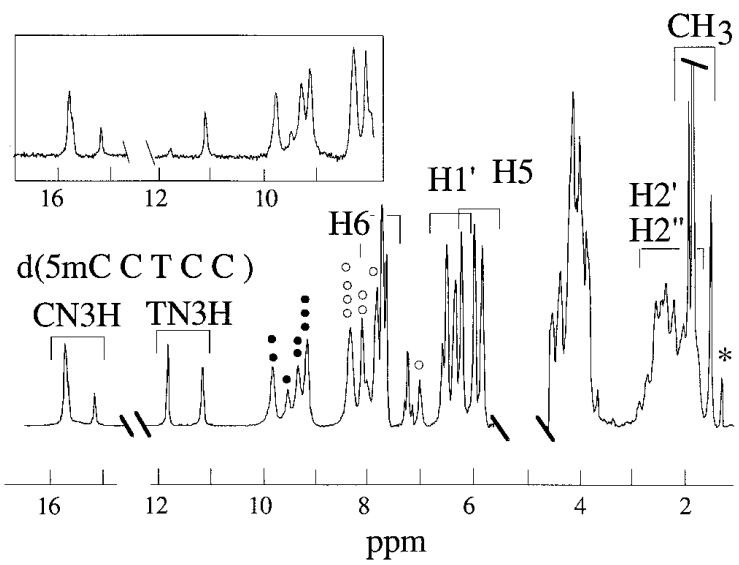

Figure 1. Proton spectrum of $[\mathrm{d}(5 \mathrm{mCCTCC})] 4$ in $\mathrm{H}_{2} \mathrm{O}$ solution. The observation of two thymidine imino proton peaks of equal area demonstrates the presence of two non-equivalent strands. The internal and the external amino protons are labelled by black and open circles, respectively. Insert: Imino protons and internal amino protons region of a spectrum recorded 0.25 second after selective inversion of the water magnetization. This saturation transfer experiment establishes the faster exchange rate of the $\mathrm{T}$ imino proton at $11.8 \mathrm{ppm}$. Experimental conditions: $t=-7^{\circ} \mathrm{C}, \mathrm{pH}$ 4.6.

(hours) as compared with the time required for the chromatography (seven minutes). The multimer and the monomer concentrations at equilibrium were measured on the elution profile of solutions prepared by dilution of an aliquot of the NMR sample. The multimer fraction at equilibrium varies as the fourth power of the monomer concentration, hence the multimer species is a tetramer. The dissociation constant is $\left(1.1 \times 10^{-4} \mathrm{M}\right)^{3}$. The chromatography profile does not disclose any dimeric component.

\section{Proton spectra}

The NMR studies were conducted on the $\mathrm{d}(5 \mathrm{mCCTCC})$ methylated derivative whose spectrum exhibits a better resolution than that of $\mathrm{d}$ (CCTCC).

The $1 \mathrm{D}$ spectrum of $[\mathrm{d}(5 \mathrm{mCCTCC})] 4$ in water at $-7^{\circ} \mathrm{C}$ is displayed in Figure 1 . The spectrum of cytidine imino and amino protons is characteristic of hemi-protonated C.C ${ }^{+}$pairs (Leroy et al., 1993). At the strand concentration of the NMR samples $(8 \mathrm{mM})$, free strand is negligible.

The presence of two thymidine imino proton peaks with identical areas shows immediately that [d(5mCCTCC $)] 4$ does not form a fully symmetrical structure with four identical strands. When the integrated area of each thymidine imino proton is set to 1 , the $15-16 \mathrm{ppm}$ region corresponds to $2.5( \pm 0.5)$ H-bonded cytidine imino protons. The thymidine imino proton at $11.84 \mathrm{ppm}$ exchanges faster than that at $11.18 \mathrm{ppm}$ as shown by the spectrum recorded 0.24 second after selective inversion of water (insert in Figure 1). 

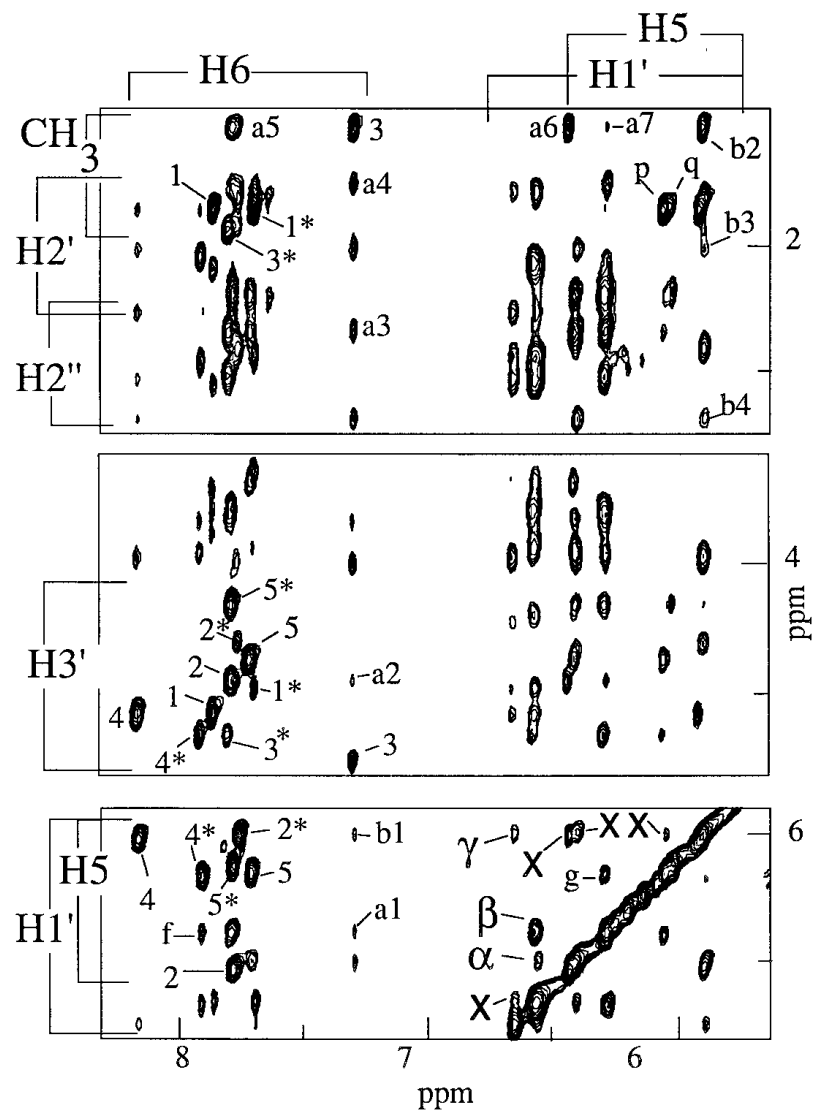

Figure 2. Expanded NOESY contour plot in ${ }^{2} \mathrm{H}_{2} \mathrm{O}$ solution (250 ms mixing time) of [d(5mCCTCC)]4. Intra-residue cross-peaks are labelled by the residue number. H5-H6, H3'-H6 and methyl-H6 cross-peaks are displayed on the lower, central and upper panels, respectively. Cross-peaks between $\mathrm{T} 3$ and $\mathrm{C} 2$ are labelled a1 (T3 H6-C2 H1'), a2 (T3 H6-C2 H3'), a3 (T3 H6-C2 H2"), a4 (T3 H6-C2 H2'), a5 (T3 methyl-C2 H6), a6 (T3 methyl-C2 H5), and a7 (T3 methyl-C2 H1'). Cross-peaks between $\mathrm{T} 3$ and $\mathrm{C} 2 *$ are labelled b1 (T3 H6-C2* H5), b2 (T3 methyl-C2* H5), b3 (T3 H2'-C2* H1'), and b4 (T3 $\left.\mathrm{H} 2 "-\mathrm{C} 2 * \mathrm{H} 1{ }^{\prime}\right)$. Cross-peaks $\mathrm{f}$ and $\mathrm{g}$ are assigned to $\mathrm{T} 3 * \mathrm{H} 1{ }^{\prime}-\mathrm{C} 4 * \mathrm{H} 6$ and to $\mathrm{T} 3 * \mathrm{H} 1-\mathrm{C} 4 * \mathrm{H} 5$.

$\mathrm{H} 1$ '-H1' cross-peaks, a characteristic feature of the i-motif, are indicated by Greek letters: $\alpha$ is assigned to the $\mathrm{mC} 1 * \mathrm{H} 1$ '-C5 H1' cross-peak, $\beta$ to the overlapping $5 \mathrm{mC} 1$ $\mathrm{H}^{\prime}-\mathrm{C} 5^{*} \mathrm{H} 1^{\prime}, \mathrm{C} 2 \mathrm{H}^{\prime}-\mathrm{T} 3^{*} \mathrm{H} 1^{\prime}$, and $\mathrm{C} 4{ }^{*} \mathrm{H} 1^{\prime}-\mathrm{C} 2 \mathrm{H} 1^{\prime}$ cross-peaks, and $\gamma$ to the $\mathrm{C} 2 * \mathrm{H} 1^{\prime}-\mathrm{C} 4 * \mathrm{H} 1$ ' cross-peaks. Exchange cross-peaks are labelled by crosses. Crosspeaks $\mathrm{p}$ and $\mathrm{q}$ are ascribed to the non-resolved interactions between the methyl groups of $5 \mathrm{mC} 1$ and $5 \mathrm{mC} 1^{*}$, and the $\mathrm{H} 5$ protons of $\mathrm{C} 5$ and $\mathrm{C} 5 *$. Experimental conditions: $t=-7^{\circ} \mathrm{C}, \mathrm{pH}$ 4.2. Spectrometer frequency $600 \mathrm{MHz}$.

The NOESY spectra of $[\mathrm{d}(5 \mathrm{mCCTCC})] 4$ in ${ }^{2} \mathrm{H}_{2} \mathrm{O}$ (Figure 2) and in $\mathrm{H}_{2} \mathrm{O}$ solution (Figure 3) display intra-residue connectivities of comparable intensities corresponding to ten spin systems, establishing the presence of two distinct strand species.

We examined the effect of temperature and $\mathrm{pH}$ on the spectrum of $[\mathrm{d}(5 \mathrm{mCCTCC})] 4$ (data not shown). At a strand concentration of $8 \mathrm{mM}$, dissociation occurs between 35 and $43^{\circ} \mathrm{C}$. At $-7^{\circ} \mathrm{C}$, the

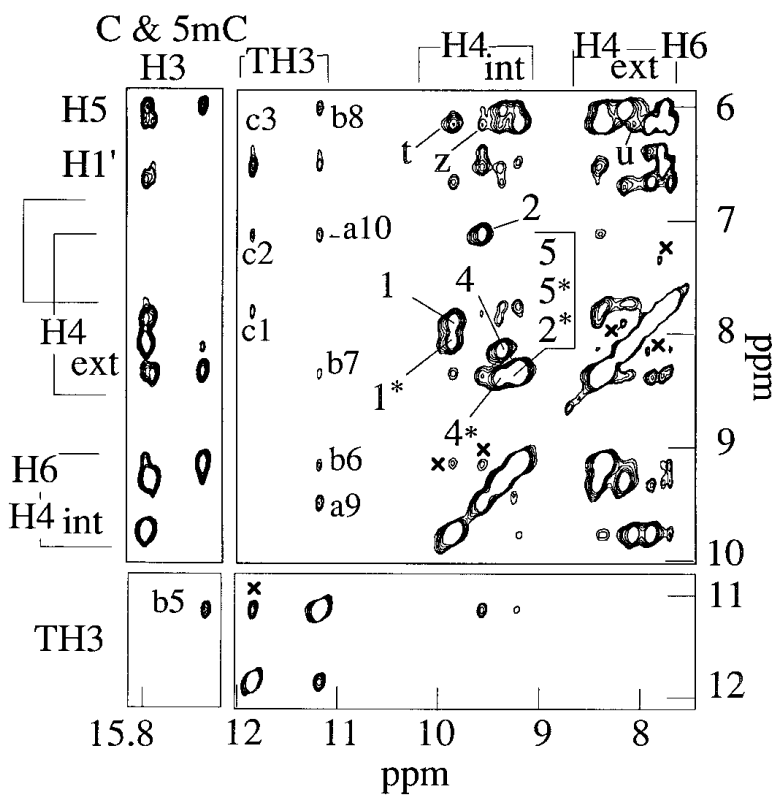

Figure 3. Exchangeable proton regions of the NOESY spectrum of $[\mathrm{d}(5 \mathrm{mCCTCC})] 4$. Intra-residue cross-peaks between internal and external amino protons are labelled by the residue number. Amino protons of the $5 \mathrm{mC} 1.5 \mathrm{mCl}^{+}, \quad \mathrm{C} 4 \cdot \mathrm{C}^{+}, \quad 5 \mathrm{mC} 1^{*} \cdot 5 \mathrm{mC} 1^{*+}, \quad \mathrm{C} 2 * \mathrm{C}^{*+}$ and $\mathrm{C} 4 * \mathrm{C} 4 *+$ base-pairs are connected to imino protons. Cross-peaks between thymidine imino protons and $\mathrm{C} 2$ protons are numbered a9 (T3 H3-C2 $\mathrm{H} 4$ int $),$ al0 (T3 H3-C2 $\mathrm{H} 44_{\text {ext }}$ ), c1 (T3* H3-C2 H6), c2 (T3* H3-C2 H4 $4_{\text {ext }}$ ), and c3 (T3* H3-C2 H5). Cross-peaks between $\mathrm{T} 3$ and $\mathrm{C} 2 *$ are labelled b5 (T3 $\mathrm{H} 3-\mathrm{C} 2 * \mathrm{H} 3)$, b6 (T3 $\mathrm{H} 3-\mathrm{C} 2 * \mathrm{H}_{4}$ int), b7 (T3 $\left.\mathrm{H} 3-\mathrm{C} 2 * \mathrm{H} 44_{\mathrm{ext}}\right)$, and b8 (T3 $\left.\mathrm{H} 3-\mathrm{C} 2 *\right)$. The cross-peaks between the non-resolved $\mathrm{H} 5$ protons of the $\mathrm{C} 55^{*} \mathrm{C} 5$ couple and the non-resolved internal amino protons of the $5 \mathrm{mC} 1-5 \mathrm{mC} 1 *$ couple are labelled t. The cross-peak between $5 \mathrm{mC} 1 * \mathrm{H}^{\text {ext }}$-C5 $\mathrm{H} 5$ is labelled u. $\mathrm{C} 2 \mathrm{H} 4_{\text {int }}$ and $\mathrm{C} 4 * \mathrm{H} 5$ are connected by cross-peak z. Experimental conditions $t=-7^{\circ} \mathrm{C}, \mathrm{pH} 4.7,250 \mathrm{~ms}$ mixing time, spectrometer frequency $360 \mathrm{MHz}$.

tetramer is stable between $\mathrm{pH} 3.5$ and 5.8, and the proton chemical shifts are $\mathrm{pH}$-independent. At all $\mathrm{pH}$ and temperatures, the concentration of the two strand species are equal.

Combined NOESY-ROESY experiments in ${ }^{2} \mathrm{H}_{2} \mathrm{O}$ (Figure 4) and in $\mathrm{H}_{2} \mathrm{O}$, show cross-peaks due to structural exchange without any contribution from the dipolar interaction. The intensity of all the exchange cross-peaks increases similarly with the temperature. The exchange process corresponds to interconversion between two strand species.

Consider for example the H5-H6 intra-residue NOESY cross-peak, and the corresponding $\mathrm{H} 5^{*}-\mathrm{H} 6^{*}$ cross-peak on the homologous residue. At $-7^{\circ} \mathrm{C}$, with a mixing time of $70 \mathrm{~ms}$ the exchange cross-peaks H6-H6* (left panel of Figure 5) and $\mathrm{H} 5-\mathrm{H} 5^{*}$ are weak. At $18^{\circ} \mathrm{C}$ with a mixing time of $250 \mathrm{~ms}$ (central panel of Figure 5), both dipolar transfer and chemical exchange occur. In that case, we also detect $\left(\mathrm{H}^{*}{ }^{*}-\mathrm{H} 5\right)$ and $(\mathrm{H} 6-\mathrm{H} 5 *)$ exchange cross-peaks (Figure 5, central panel). From the pattern of the exchange cross-peaks, we defined 


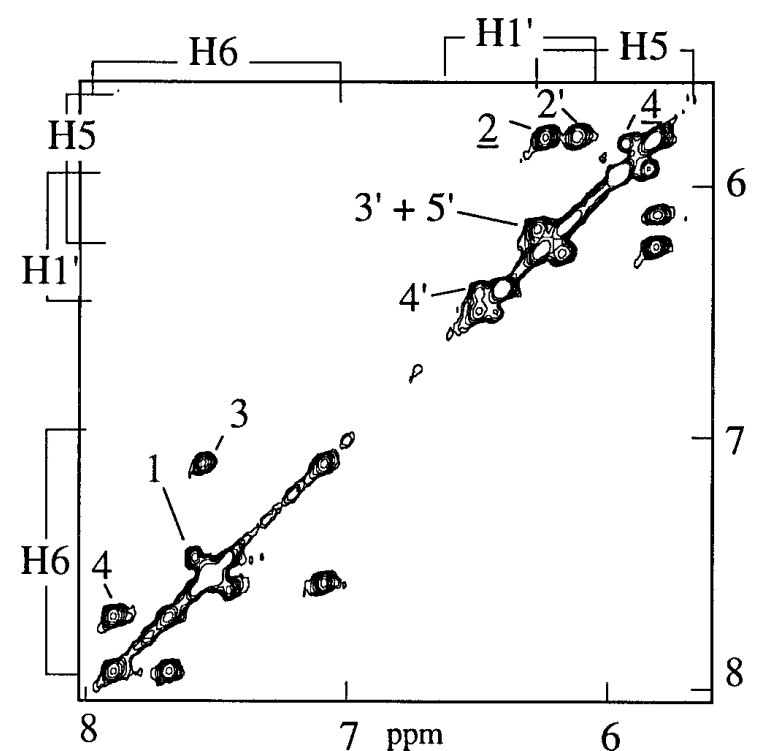

Figure 4. Pure chemical exchange experiment on the [d $(5 \mathrm{mCCTCC})] 4$ tetramer at $20^{\circ} \mathrm{C}$ (mixing time $150 \mathrm{~ms}$ ) in ${ }^{2} \mathrm{H}_{2} \mathrm{O}$ solution. The cross-relaxation is suppressed by a combination of interleaved NOESY and ROESY pulses (Fejzo et al. 1991). The exchange cross-peaks are labelled by the residue number of the exchanging couple. Primed numbers indicate $\mathrm{H} 1$ '- $\mathrm{H} 1$ ' exchange cross-peaks. The number of the H5-H5 exchange cross-peaks is underlined. The exchange cross-peaks $\mathrm{C} 1 \mathrm{H} 6-\mathrm{C} 1 * \mathrm{H} 6, \mathrm{C} 2$ H6-C2* $\mathrm{H} 6, \mathrm{C} 1 \mathrm{H}^{\prime}-\mathrm{C} 1 *{ }^{*} \mathrm{H} 1{ }^{\prime}$, and $\mathrm{C} 1 \mathrm{H}_{5}-\mathrm{C} 1 *$ H5 corresponding to couples of exchanging protons insufficiently resolved are too close of the diagonal to be detected.

five couples of homologue residues which occupy the same sequential position on each $\mathrm{d}(5 \mathrm{mCCTCC})$ strand. From the comparison of NOESY and of exchange ROESY-NOESY spectra, we could identify the cross-peaks which have no exchange contribution.

\section{Tetramer symmetry}

The characteristic amino-H2'/H2" cross-peaks (labelled 1 to 13 in Figure 6), the inter-residue connectivities between $\mathrm{H} 1$ '-H1' protons (Greek letters in Figure 2), and the strong intra-residue H3'-H6 cross-peaks (Figure 2) observed on the NOESY spectra of $[\mathrm{d}(5 \mathrm{mCCTCC})] 4$ provide evidence for an i-motif arrangement.

Figure 7 shows three hypothetical arrangements which could account for the formation of an i-motif tetramer containing two distinct strands in identical proportions: a single symmetrical tetramer consisting of two distinct symmetrical duplexes (Figure 7a), or consisting of two identical asymmetrical duplexes (Figure 7b); an equimolar mixture of two distinct symmetrical tetramers (Figure 7c).

The observation of NOE connectivities between both strand species eliminates the strand arrangement of Figure 7c. For example, both thymidine imino protons are connected to the same external amino proton (cross-peaks c2 and a10, Figure 3). The same NOESY spectrum shows that the cytidine imino protons are connected to a single amino proton group. This establishes that the hemi-protonated $\mathrm{C} \cdot \mathrm{C}^{+}$pairs are symmetrical on the NMR time scale and excludes the non-symmetrical base-pairing of Figure $7 \mathrm{~b}$. Thus we are left with the strand arrangement of Figure $7 \mathrm{a}$, corresponding to the association of two distinct symmetrical duplexes anti-parallel to one another. Henceforth, one duplex made of two identical strands a and $\mathrm{c}$ will be designated $\{\mathrm{ac}\}$, and the second duplex will be similarly indicated $\{b d\}$. The residues of the $\{b d\}$ duplex will be identified by a star.

\section{Proton assignment and intercalation topology}

In all i-motif structures investigated so far by NMR (Gehring et al., 1993; Leroy \& Guéron, 1995), and more generally in most DNA structures, the H3' proton of 3'-end residues is shifted upfield from those connected to a phosphate group. We thus assign the peaks at 4.39 and $4.6 \mathrm{ppm}$ to the $\mathrm{H}^{\prime}$ protons of cytidine $\mathrm{C} 5$ and $\mathrm{C} 5 *$ (middle panel of Figure 2 and Table 1). We arbitrarily assign the H3' proton at $4.61 \mathrm{ppm}$ to $\mathrm{C} 5$. The $5 \mathrm{mC} 1-5 \mathrm{mC} 1$ * couple is readily identified by the intra-residue connectivities with the methyl protons (upper panel, Figure 2).

The NOE connectivities observed between the couples $5 \mathrm{mC} 1-5 \mathrm{mC} 1 *$ and $\mathrm{C} 5-\mathrm{C} 5 *$ are consistent with the intercalation of $\{\mathrm{ac}\}$ and $\{\mathrm{bd}\}$ duplexes in a head-to-tail orientation, resulting in the stacking of $5 \mathrm{mC} 1$ with $\mathrm{C}^{*}$ at one end of the tetramer, and of $5 \mathrm{mC} 1 *$ with $\mathrm{C} 5$ at the other end. They include: (1) cross-peaks between the non-resolved $5 \mathrm{mC} 1$ or $5 \mathrm{mC} 1 *$ methyl protons and the $\mathrm{H} 5$ protons of $\mathrm{C} 5$ and $\mathrm{C}^{*}$ (peaks labelled $\mathrm{p}$ and $\mathrm{g}$ on Figure 2); (2) cross-peaks between the cytidine methyl protons and the amino protons of the C5 C5* couple (cross-peaks $\mathrm{r}$ and s, Figure 6); (3) cross-peaks between $\mathrm{C} 5 \mathrm{H} 5$ and $\mathrm{C} 5{ }^{*} \mathrm{H} 5$ protons and both internal and external amino protons of the methylated cytidine residues ( $t$ and $u$, Figure 3 ).

The protons of the $\mathrm{C} 5$ and $\mathrm{C}^{*}$ residues are NOE-connected exclusively to the $5 \mathrm{mC} 1 *-5 \mathrm{mC} 1$. The latter couple is also connected to a second couple of exchanging cytidine residues. This shows that $\mathrm{C} 5$ and $\mathrm{C} 5 *$ terminate the tetramer, and leads to the intercalation scheme displayed in Figure 8. The scheme identifies the second couple of cytidine residues as $\mathrm{C} 4$ and $\mathrm{C} 4 *$. Characteristic reciprocal amino-H2' / H2" cross-peaks connect $5 \mathrm{mC} 1$ and $\mathrm{C}^{*} *$ (cross-peaks 5, 6, 9, and 10 between $5 \mathrm{mC} 1 \mathrm{H} 2$ '/H2" and $\mathrm{C}^{*}$ amino protons, and cross-peaks 1 and 3 between the internal amino proton of $5 \mathrm{mC} 1$ and C4* H2'/H2" protons, Figure 6). Similar connections are seen between $5 \mathrm{mC} 1 *$ and $\mathrm{C} 4$ (cross-peaks 2, 4, and 13 in Figure 6). The amino protons of the C4-C4* couple are also connected to the non-resolved methyl groups of the $5 \mathrm{mC} 1-5 \mathrm{mCl} 1 *$ couples.

Next, $\mathrm{C} 2 *$ is identified by the $\mathrm{H} 1{ }^{\prime}-\mathrm{H} 1$ ' cross-peak with $\mathrm{C} 4$ (cross-peak $\gamma$, Figure 2, lower panel). The 


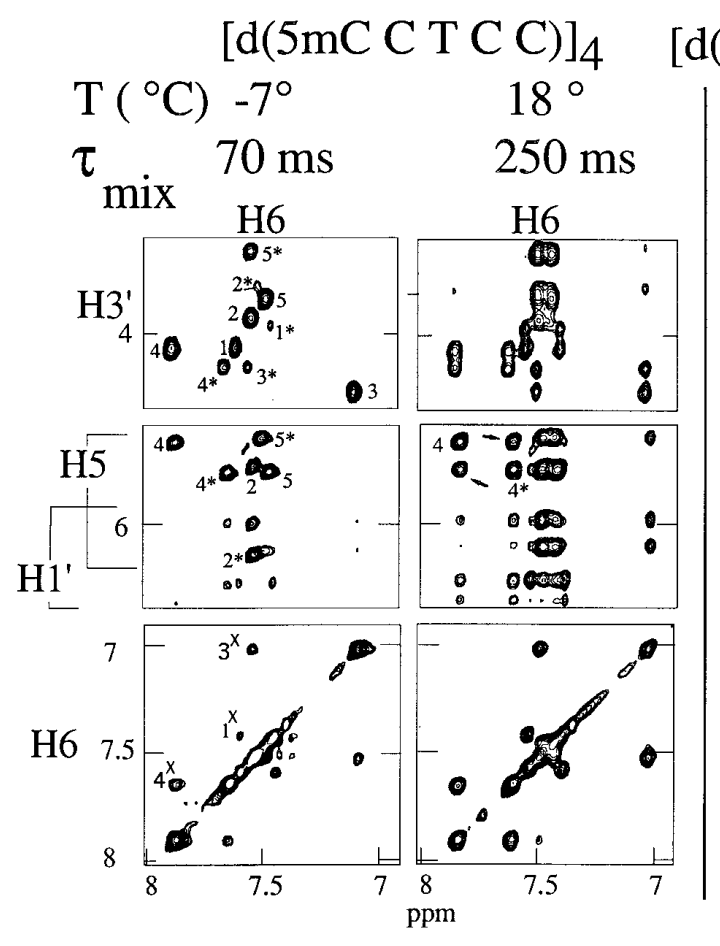

$[\mathrm{d}(5 \mathrm{mC} \mathrm{C} \mathrm{U} \mathrm{C} \mathrm{C})]_{4}$

$32{ }^{\circ} \mathrm{C}$

$250 \mathrm{~ms}$

$\mathrm{H} 6$

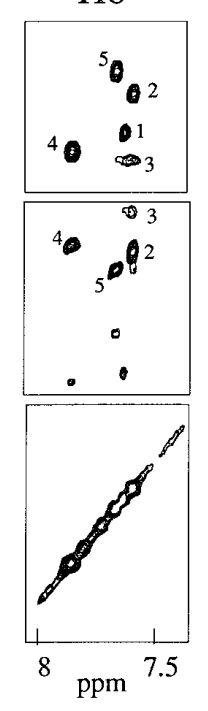

Figure 5. Comparison of the NOESY spectra of $[\mathrm{d}(5 \mathrm{mCCTCC})] 4$ and $[\mathrm{d}(5 \mathrm{mCCUCC})] 4$ in ${ }^{2} \mathrm{H}_{2} \mathrm{O}$ solution. Left panel: the NOESY spectrum of $[\mathrm{d}(5 \mathrm{mCCTCC})] 4$ at $-7^{\circ} \mathrm{C}$ (70 ms mixing time) shows ten spin systems corresponding to two nonequivalent duplexes. The intraresidue cross-peaks are labelled by the residue number. Upper row: H3'-H6 cross-peaks. Central row: H5-H6 cross-peaks. The H6-H6 exchange cross-peaks (crosses) reflect interconversion of the duplexes.

Central panel: At $18^{\circ} \mathrm{C}(250 \mathrm{~ms}$ mixing time) the interconversion rate between the duplexes is fast enough to give rise to cross-peaks involving a combination of dipolar and exchange transfers during the mixing time. The $\mathrm{C} 4 \mathrm{H} 6-\mathrm{C} 4 * \mathrm{H} 5$ and the $\mathrm{C} 4 \mathrm{H} 5-\mathrm{C} 4 * \mathrm{H} 6$ cross-peaks are representative of this phenomenon (arrows).

Right panel: The NOESY spectrum of $[\mathrm{d}(5 \mathrm{mCCUCC})] 4$ at $32^{\circ} \mathrm{C}$ (250 ms mixing time) shows only five spin systems, due to equivalence of the four d(5mCCUCC) strands on the NMR time-scale at this temperature. homologous residues, $\mathrm{C} 2$ and $\mathrm{C} 4 *$, are connected by a NOE between the internal amino proton of $\mathrm{C} 2$ and C4* $\mathrm{H} 5$ (cross-peak $\mathrm{z}$ in Figure 3).

The characteristics NOEs between $\mathrm{C} 2 *$ amino protons and $\mathrm{T} 3 \mathrm{H} 2{ }^{\prime} / \mathrm{H} 2 "$ protons (cross-peaks 7, 8, 11 , and 12 on Figure 6) show that T3 is intercalated

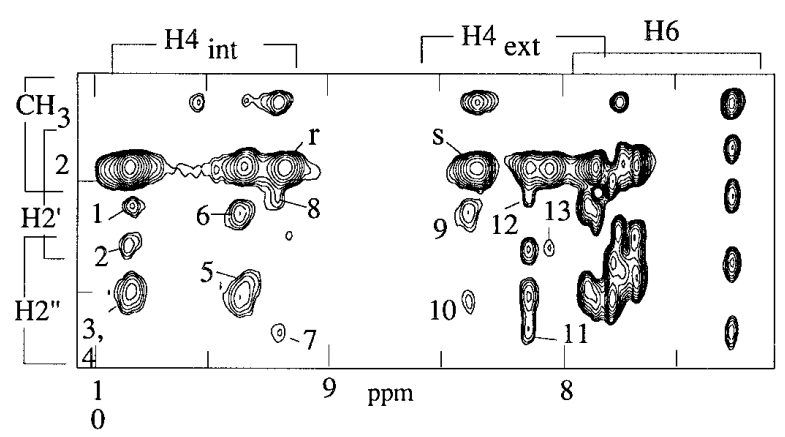

Figure 6. Expanded NOESY contour plot of [d $(5 \mathrm{mCCTCC})] 4$ in $\mathrm{H}_{2} \mathrm{O}$ solution at $-5^{\circ} \mathrm{C}(150 \mathrm{~ms}$ mixing time). Cross-peaks 1 to 13 correspond to the NOEs between amino protons and $\mathrm{H} 2$ '/H2" protons which determine the intercalation topology: $1\left(5 \mathrm{mC} 1 \mathrm{H} 4_{\text {int }}-\mathrm{C} 4\right.$ * $\left.\mathrm{H} 2^{\prime}\right) ; 2\left(5 \mathrm{mC}^{*}{ }^{*} \mathrm{H}_{4}{ }_{\text {int }}-\mathrm{C} 4 \mathrm{H} 22^{\prime}\right) ; 3$ ( $\left.5 \mathrm{mC} 1 \mathrm{H} 4_{\text {int }}-\mathrm{C} 4 * \mathrm{H} 2^{\prime \prime}\right) ; 4$ (5mC1* $\left.\mathrm{H}{ }_{\text {int }}-\mathrm{C} 4 \mathrm{H} 2 "\right) ; 5$ (C4* $\mathrm{H}_{\text {int }}-5 \mathrm{mC} 1 \mathrm{H} 2$ "); 6 (C4*

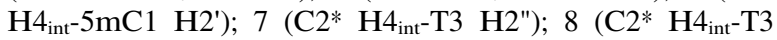
$\left.\mathrm{H} 2^{\prime}\right) ; 9$ (C4* $\left.\mathrm{H} 4_{\mathrm{ext}}-5 \mathrm{mC} 1 \mathrm{H} 2 "\right) ; 10$ (C4* $\mathrm{H} 4_{\mathrm{ext}}-5 \mathrm{mC} 1 \mathrm{H} 2$ '); 11 (C4* $\left.\mathrm{H} 4_{\text {ext }}-5 \mathrm{mC} 1 \mathrm{H} 2 "\right) ; 12$ (C2* $\mathrm{H} 4_{\text {ext }}$-T3 H2'); 13 (5mC1* $\left.\mathrm{H} 4_{\text {ext }}-\mathrm{C} 4 \mathrm{H} 2^{\prime}\right)$. Cross-peaks between the non-resolved methyl protons of the $5 \mathrm{mC} 1-5 \mathrm{mC}^{*}$ couple and the non-resolved internal and external amino protons of the C5-C5* couple are labelled $\mathrm{r}$ and $\mathrm{s}$, respectively. into the i-motif in position adjacent of $\mathrm{C} 2 *$. T3 exhibits several other connectivities with $\mathrm{C} 2 *$ ring and sugar protons (cross-peaks b1-b4 in Figure 2, and b5 to b8 in Figure 3). Surprisingly, T3 is also connected by sequential NOEs with $\mathrm{C} 2$ (crosspeaks a1 to a7, Figure 2, and cross-peaks a9 and a10, Figure 3 ) suggesting that it is stacked with $\mathrm{C} 2$.

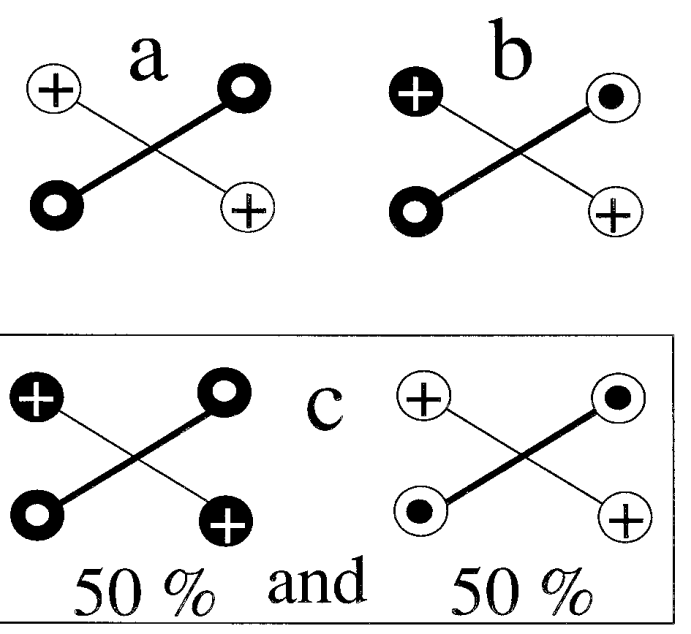

Figure 7. End-on-view of three hypothetical strand arrangements in an i-motif tetramer containing two kind of strands (open and closed circle) in identical proportions. The strand orientation is indicated by the symbols $\bigcirc$ and + . Base-pairing between duplexes is indicated by thin lines. 
Table 1. Proton chemical shifts $(\mathrm{ppm})$ in the $[\mathrm{d}(\mathrm{mCCTCC})] 4$ tetramer at $-7^{\circ} \mathrm{C}$

\begin{tabular}{|c|c|c|c|c|c|c|c|c|c|c|}
\hline & H3 & $\mathrm{H} 4_{\text {int }}$ & $\mathrm{H} 4_{\text {ext }}$ & H6 & $\mathrm{H} 5 / \mathrm{CH} 3$ & $\mathrm{H} 1^{\prime}$ & $\mathrm{H} 2^{\prime}$ & $\mathrm{H} 2 "$ & H3' & $\mathrm{H} 4^{\prime}$ \\
\hline $\mathrm{mC} 1$ & 15.711 & 9.86 & 8.05 & 7.85 & 1.87 & 6.54 & 2.12 & 2.59 & 4.83 & 4.10 \\
\hline $\mathrm{C} 2$ & a & 9.55 & 7.03 & 7.78 & 6.41 & 6.25 & 1.77 & 2.38 & 4.69 & 4.02 \\
\hline $\mathrm{T} 3$ & 11.18 & - & - & 7.28 & 1.54 & 6.39 & 2.04 & 2.74 & 5.04 & 4.22 \\
\hline $\mathrm{C} 4$ & 15.71 & 9.35 & 8.13 & 8.16 & 5.89 & 6.63 & 2.31 & 2.58 & 4.84 & 4.18 \\
\hline $\mathrm{C} 5$ & a & 9.19 & 8.34 & 7.71 & 6.02 & 6.38 & 2.23 & 2.39 & 4.61 & 3.90 \\
\hline $\mathrm{mC} 1$ * & 15.711 & 9.84 & 7.86 & 7.69 & 1.88 & 6.54 & 1.80 & 2.48 & 4.73 & 4.14 \\
\hline $\mathrm{C} 2 *$ & 15.15 & 9.56 & 9.22 & 7.74 & 5.86 & 5.86 & 1.80 & 2.46 & 4.54 & 4.20 \\
\hline T3* & 11.84 & - & - & 7.79 & 1.96 & 6.27 & 2.39 & 2.52 & 4.92 & 4.04 \\
\hline $\mathrm{C} 4 *$ & 15.6 & 9.36 & 8.39 & 7.91 & 6.03 & 6.55 & 2.08 & 2.50 & 4.92 & 4.16 \\
\hline $\mathrm{C} 5^{*}$ & a & 9.19 & 8.34 & 7.78 & 6.00 & 6.26 & 2.23 & 2.23 & 4.39 & 3.98 \\
\hline
\end{tabular}

Thymidine T3* shows NOEs to C2 (cross-peaks c1 to $\mathrm{c} 3$, Figure 3 ), to $\mathrm{C} 2 *$ (cross-peaks $\mathrm{T} 3 \mathrm{CH} 3-\mathrm{C} 2$ $\mathrm{H}^{\prime}$ ), and to $\mathrm{C}^{*}$ (cross-peaks $\mathrm{f}$ and $\mathrm{g}$ between ${ }^{*} 3^{*}$ $\mathrm{H} 1$ ' and $\mathrm{C}^{*}{ }^{*} \mathrm{H} 6 / \mathrm{H} 5$, Figure 2, lower panel).

With the remarkable exception of the $\mathrm{C} 2$ external amino proton, which is shifted by $1.34 \mathrm{ppm}$ upfield from that of $\mathrm{C}^{*}$, chemical shift differences between protons belonging to homologous residues are maximum for the T3-T3* couple, and decrease in both $3^{\prime}$ and $5^{\prime}$ directions (Table 1).

\section{Structural analysis}

The structure of $[\mathrm{d}(5 \mathrm{mCCTCC})] 4$ was computed using the simulated annealing method (Nilges, 1993) with the inter-residue distance restraints displayed in Figure 8. The distances were computed from the build-up of 55 NOESY crosspeaks as described in Materials and Methods. All the restraints used in the structure calculation are shown in the histogram displayed in Figure 9.

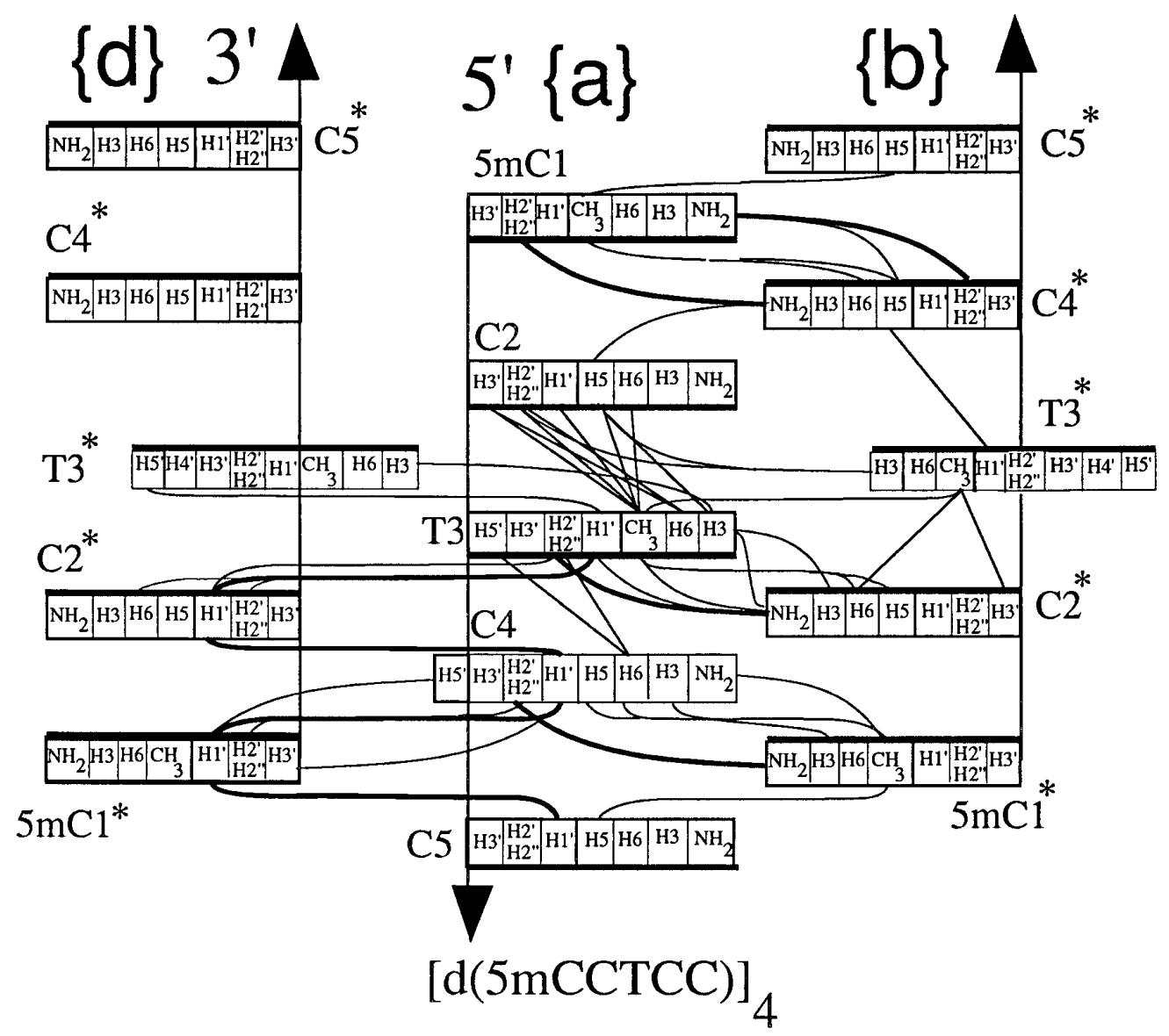

Figure 8. Schematic representation of the inter-residue distance restraints used to compute the $[\mathrm{d}(5 \mathrm{mCCTCC})] 4$ structure. The distance restraints between strand $\{a\}$ and strand $\{b\}$, and between strand $\{a\}$ and strand $\{d\}$ define the inter-strand relations across the wide groove and the narrow groove, respectively. The amino- $\mathrm{H} 2$ ' / $\mathrm{H} 2$ " and the $\mathrm{H} 1$ '-H1' inter-strand connectivities indicated by heavy lines are characteristic of the i-motif structure and determine the intercalation topology. 

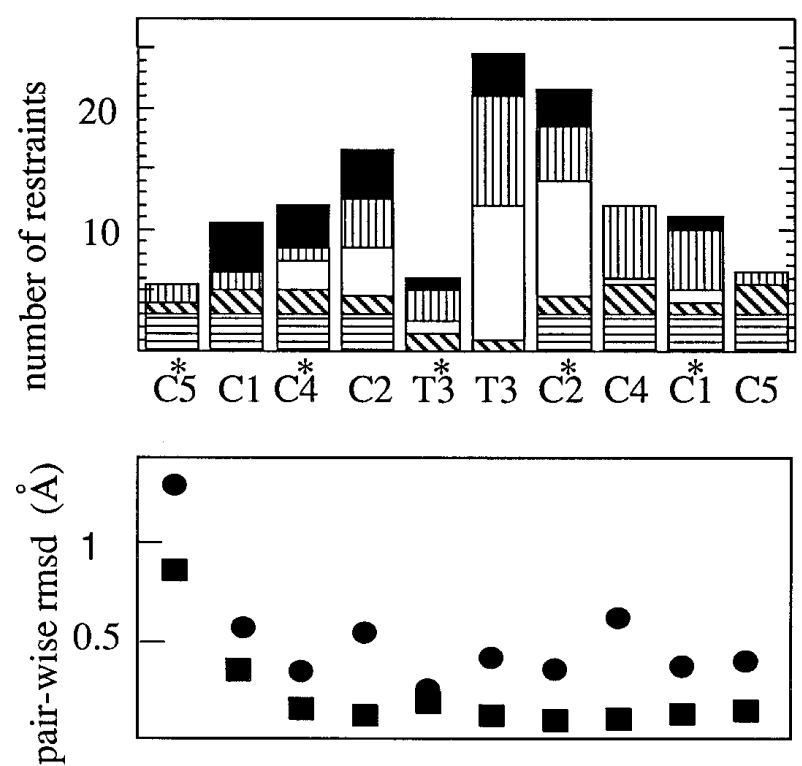

Figure 9. Upper panel: Distribution of the NMR-derived distance restraints used in the structure calculation of $[\mathrm{d}(5 \mathrm{mCCTCC})] 4$. The intra-residue cross-peaks are counted as one, and the inter-residue restraints as one half for each partner. Black area, distances involving an exchangeable proton; vertically hatched area, interresidue distances involving two non-exchangeable protons. Blank area, the repulsive restraints reflecting the absence of direct NOE cross-peaks at long mixing times. The diagonally hatched area represents restraints on $\mathrm{H}$-bond lengths used to define the $\mathrm{C} \cdot \mathrm{C}^{+}$pairing and the horizontally hatched area the intra-residue distance restraints.

Lower panel: pair-wise RMSD of the heavy atom positions for the bases (squares) and the sugar-phosphate backbones (circles). The RMSD are computed from the pair-wise comparison of 13 conformers aligned on the $\mathrm{C} 1$ ' positions.

We computed a set of 24 conformers. All had the same topology. The structural parameters were derived from the analysis of 13 conformers selected for their low energy associated with NOE violations. Violations from ideal geometry are displayed in Table 2.

The tetramer is formed by two parallel duplexes intercalated head-to-tail, differing by the arrangement of the thymidine residues (Figure 10).

In the $\{\mathrm{ac}\}$ duplex, the short inter-strand distance found in the computed structure between T3, H3

Table 2. Violations and deviations from ideal geometry in structural computations

\begin{tabular}{ll}
\hline Number of NOE violations larger than $0.2 \AA$ & 6 \\
Largest NOE violation $(\AA)$ & 0.29 \\
RMSD of input distance restraints $(\AA)$ & 0.065 \\
Number of ideal bond angle violations larger than $6^{\circ}$ & 2 \\
Largest ideal bond angle violation $\left(^{\circ}\right)$ & 6.2 \\
RMSD from ideal bond angles & 1.3 \\
Number of improper violations larger than $5^{\circ}$ & 0 \\
RMSD from ideal impropers $\left({ }^{\circ}\right)$ & 0.59 \\
Bond violation larger than $0.05(\AA)$ & 0 \\
RMSD from ideal bonds $(\AA)$ & 0.007 \\
\hline
\end{tabular}

and T3 $02,2.15( \pm 0.15) \AA$, shows that the thymidine residues are base-paired. This pair is symmetrical (a single spin system) and it is stacked into the i-motif between the $\mathrm{C} 2 \cdot \mathrm{C} 2^{+}$pair of the same duplex and the $\mathrm{C} 2 * \mathrm{C} 2 *$. pair of the other duplex.

The thymidines $\mathrm{T} 3 *$ of the $\{\mathrm{bd}\}$ duplex are unpaired and not stacked. They lie symmetrically in the wide grooves along the $\mathrm{C} 2 \cdot \mathrm{C}^{+}$base-pair. This position is imposed by the strong T3* $\mathrm{H} 3-\mathrm{C} 2$ H5 cross-peak (labelled c3 in Figure 3).

Except for the $\mathrm{C}^{*}$ residue which is poorly defined by the NMR data, the RMSD plotted as a function of the stacking order in the lower panel of Figure 9 shows a uniform definition of the structure. The overall pair-wise RMSD is $0.9 \AA$. The geometrical parameters are presented in Table 3.

For all residues, the glycosydic conformation is anti with glycosidic torsion angles ranging from $-107^{\circ}$ to $-154^{\circ}$. Most sugar puckers are N-type. The tetramer has two identical narrow grooves and two identical wide grooves. The inter-strand phosphatephosphate distances vary from 9 to $12.7 \AA$ across the narrow grooves and from 13.4 to $16.1 \AA$ across the wide grooves (Table 4). The flatness of the bases may be related to the small stacking distance (3.06 $\AA$ on the average). The duplexes are righthanded. The $\mathrm{C} 1$ '-C1' distance between the paired bases ranges from 9.2 to $10 \AA$ for the cytidines and is equal to $10.4 \AA$ for the T3.T3 pair. This distance is larger in the case of the non-stacked T3* residues, in relation with the backbone distortions at this point.

\section{Duplex interconversion kinetics}

Due to their large chemical shift difference, thymidine H6 protons are good markers of duplex interconversion. Figure 11 shows magnetization transfer from T3 H6 to $\mathrm{T}^{*} \mathrm{H} 6$ as a function of the time during which T3 H6 is saturated. The interconversion time was computed from the fits displayed in the right panel using equation (1). Magnetization transfer experiments performed on the H6 protons of the $\mathrm{C} 4-\mathrm{C} 4 *$ couple gave identical interconversion times. The temperature dependence of the duplex interconversion time (Figure 11) corresponds to an activation energy of $94 \mathrm{~kJ} / \mathrm{mol}$. The interconversion time is unchanged when the sample is diluted by a factor of two. It decreases twofold in $0.18 \mathrm{M}$ potassium phosphate (Figure 12, central panel), and threefold in $0.7 \mathrm{M}$ ammonium chloride.

\section{Proton exchange with water}

At $-70^{\circ} \mathrm{C}$, imino protons of $\mathrm{C} 5, \mathrm{C}^{*}$ and $\mathrm{C} 2$ exchange too rapidly to give rise to intra-residue NOEs with the amino protons (Figure 3 ). The exchange times of $\mathrm{T} 3 *, \mathrm{~T} 3$, and $\mathrm{C} 2 *$ imino protons are plotted versus temperature on Figure 12. The exchange time of $\mathrm{T}^{*}$ imino proton is close to that measured on the monomer, as expected for a non-paired residue. 


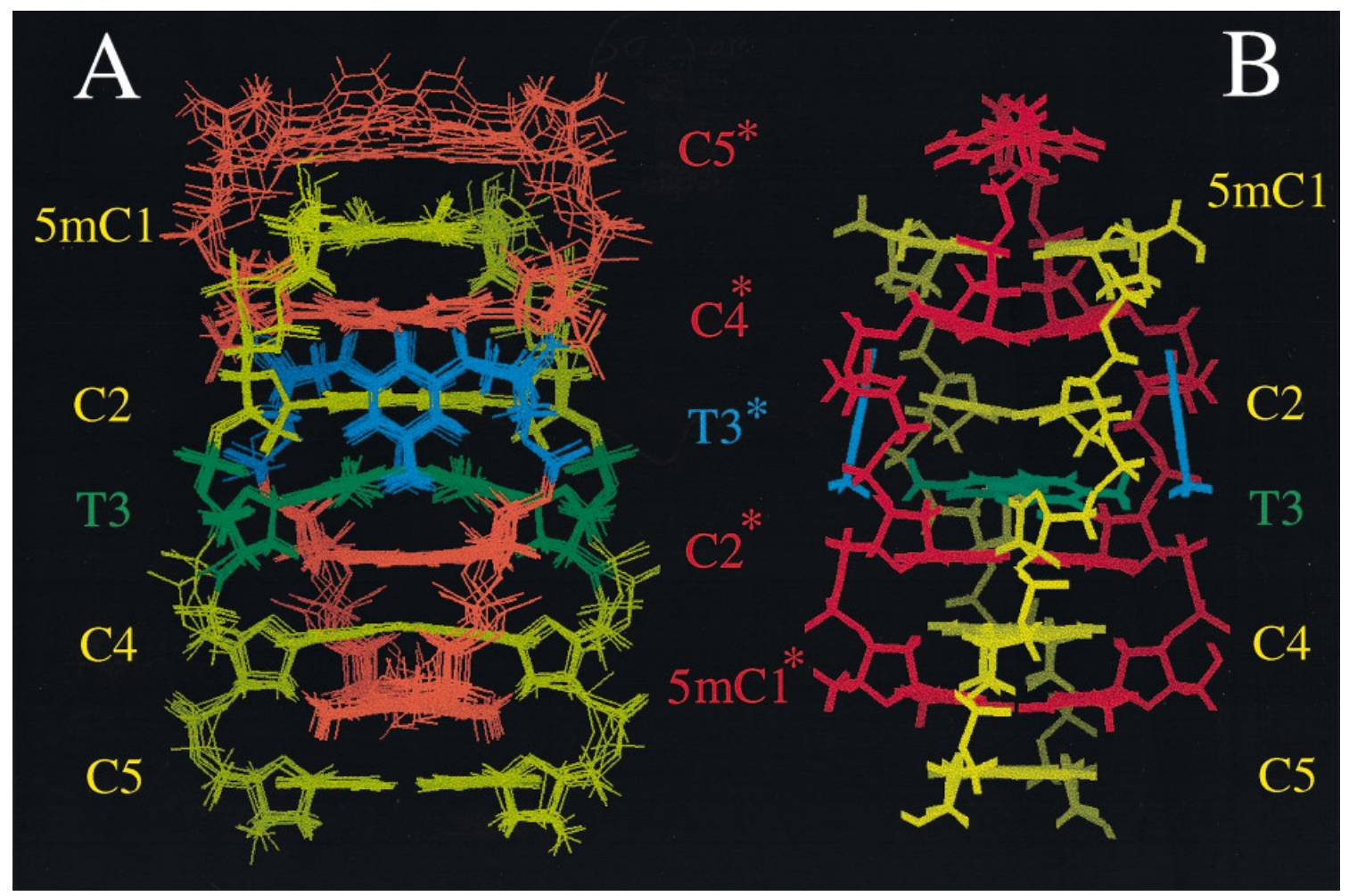

Figure 10. Computed structure of [d(5mCCTCC $) 4]$. A, Wide groove view of the eight lowest-energy conformers. $B$, View normal to the minor groove of the lowest energy conformer. The yellow cytidine residues belong to the duplex whose thymidine residues are base-paired (green T3.T3 pair). In the second duplex, the cytidine residues are red and the non-base-paired thymidine residues $T 3^{*}$ are blue.

The exchange time of the imino proton of the $\mathrm{C} 2{ }^{*} \cdot \mathrm{C} 2{ }^{*+}$ pair is equal to the duplex interconversion time. This corresponds to an exchange time in the $\mathrm{C} 2^{*} \cdot \mathrm{C} 2{ }^{*+}$ pair which is longer than the duplex lifetime. Interconversion of the duplex changes the $\mathrm{C} 2{ }^{*}-\mathrm{C} 2^{*+}$ pair into a $\mathrm{C} 2 \cdot \mathrm{C} 2^{+}$pair from which imino proton exchange is very fast, as mentioned above.

Hydroxyl and phosphate catalysis of imino proton of the non-base-paired $\mathrm{T} 3 *$ occur at rates similar to those of the monomeric thymidine.

In the presence of $0.18 \mathrm{M}$ phosphate ( $\mathrm{pH}$ 5.6), the exchange rate of the $\mathrm{T} 3 *$ imino proton is faster than the duplex interconversion rate, and the exchange rate of the $\mathrm{T} 3$ imino proton is equal to the duplex interconversion rate. In this case, $\mathrm{T} 3$ imino proton exchange is controlled by duplex interconversion, as in the case of $\mathrm{C} 2 * / \mathrm{C} 2$ just described (Figure 12, central panel).

Upon addition of $0.7 \mathrm{M}$ ammonia at $\mathrm{pH}$ 5.6, i.e. in the presence of $12.5 \times 10^{-4} \mathrm{M}$ of the acceptor species $\mathrm{NH}_{3}$, the exchange time of T3 imino proton remains identical to the duplex interconversion time. In such drastic conditions of catalysis, the exchange rate of the imino proton of the thymidine monomer is $3 \times 10^{4} \mathrm{~s}^{-1}$ (Guéron et al., 1989). The lack of effect of $\mathrm{NH}_{3}$ on proton exchange $\left(<3 \mathrm{~s}^{-1}\right)$, gives an upper bond of $10^{-4}$ for the dissociation constant of the T3.T3 pair at $15^{\circ} \mathrm{C}$.

At $\mathrm{pH} 4.7$ in the absence of added exchange catalyst, T3 imino proton exchange is controlled by the rate of duplex interconversion (below $20^{\circ} \mathrm{C}$ ) or by the exchange rate of $\mathrm{T} 3^{*}$ imino proton (above $20^{\circ} \mathrm{C}$ ).

Imino and amino proton exchange times measured in real time at $0^{\circ} \mathrm{C}$ from a series of spectra recorded after dilution of a protonated sample in ${ }^{2} \mathrm{H}_{2} \mathrm{O}$ are displayed in Table 5. Two imino protons exchange in 730 seconds. The resolved low field proton belongs to the $\mathrm{C} 4 \cdot \mathrm{C}^{+}$pair. Since the exchange time is much larger than the duplex interconversion time, the second slow-exchanging imino proton is necessarily that of the $\mathrm{C} 4 * \cdot \mathrm{C} 4^{*+}$ pair.

Internal and external amino protons exchange at distinct rates. The exchange rates of the amino protons of the $\mathrm{C} 4-\mathrm{C} 4 *$ and $\mathrm{C} 1-\mathrm{C} 1 *$ couples are particularly slow (Table 5).

\section{The 5mCCUCC tetramer}

Gel filtration chromatography shows that the deoxy-uridine derivative, $\mathrm{d}(5 \mathrm{mCCUCC})$, forms a tetramer whose stability is similar to that of $\mathrm{d}(5 \mathrm{mCCTCC})$.

\section{Tetramer symmetry and interconversion kinetics}

The 1D NMR spectrum of $[\mathrm{d}(5 \mathrm{mCCUCC})] 4$ is quite comparable to that of $[\mathrm{d}(5 \mathrm{mCCTCC})] 4$. At $0^{\circ} \mathrm{C}$, the NOESY spectra exhibit also two exchanging spin systems for each residue, but the intensities 


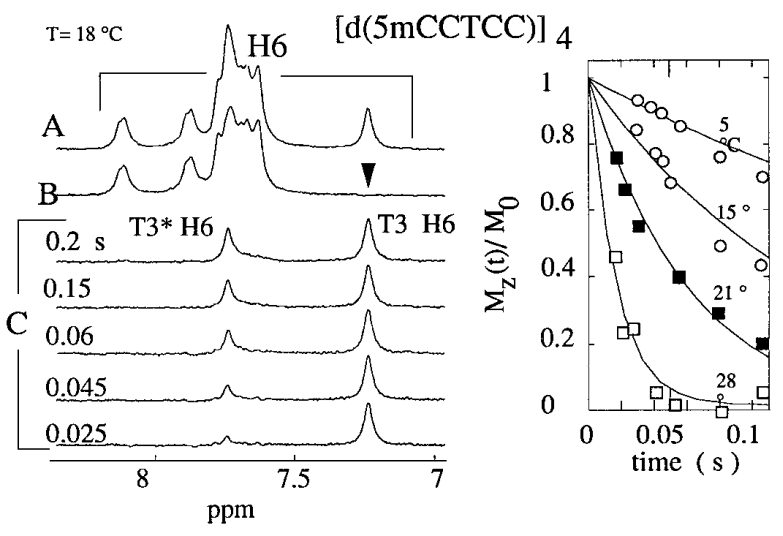

Figure 11. Magnetization transfer experiment between the T3 H6 proton of the $\{$ ac $\}$ duplex and its homologue (T3* H6) on the $\{\mathrm{bd}\}$ duplex. Left side: H6 proton region of the $[\mathrm{d}(5 \mathrm{mCCTCC})] 4$ spectrum. A, Reference spectrum; B, T3 H6 (arrow) was selectively saturated during 0.15 second prior to detection. C, Difference spectra between the spectrum in A and spectra obtained after saturation of T3 H6 during the delay indicated on the Figure. Right side: Magnetisation of T3* $\mathrm{H} 6$ as a function of the time during which T3 H6 was maintained saturated. The duplex interconversion time was computed using expression (1). The exchange times displayed in Figure 12 are derived from the fits.

of the exchange cross-peaks indicate a faster duplex interconversion rate in the case of the uridine oligomer. Indeed, the NMR lines of homologous protons belonging to most of the exchanging residues coalesce between $10^{\circ} \mathrm{C}$ and $30^{\circ} \mathrm{C}$. The NOESY spectrum recorded just below the melting transition at $32^{\circ} \mathrm{C}$ exhibits only five spin systems (Figure 5, right panel). The narrow cytidine intra-residue $\mathrm{H} 6-\mathrm{H} 5$ and $\mathrm{H} 3$ '-H6 cross-peaks show that the duplex interconversion rate is fast enough to average the environment of these protons. The environment of the homologous protons which have a large chemical shift difference is incompletely averaged on the $32^{\circ} \mathrm{C}$ spectrum, as shown by the large linewidth of the uridine $\mathrm{H} 6$ proton and the absence of the $\mathrm{C} 2$ external amino proton on the NOESY spectrum in $\mathrm{H}_{2} \mathrm{O}$ at $32^{\circ} \mathrm{C}$ (data not shown).

The interconversion time of the $[\mathrm{d}(5 \mathrm{mCCUCC})] 2$ duplexes measured by magnetization transfer, $25 \mathrm{~ms}$ at $0^{\circ} \mathrm{C}$, is 30 times shorter than that measured on the tetramer of $\mathrm{d}(5 \mathrm{mCCTCC})$ (Figure 12, right panel). The activation energy of the duplex interconversion rate is $55 \mathrm{~kJ} / \mathrm{mol}$.

\section{Proton assignment and intercalation topology of the motion-averaged structure of $[\mathrm{d}(5 \mathrm{mCCUCC})] 4$}

We design by the subscript av the motion averaged NMR peaks. The spectrum is assigned as explained above in the case of $[\mathrm{d}(5 \mathrm{mCCTCC})] 4$, using the characteristic $\mathrm{H} 1$ '-H1' and amino-H2'-H2" cross-peaks detected on the NOESY spectrum at $32^{\circ} \mathrm{C}$. The $\mathrm{C} 5_{\mathrm{av}}$ residue, identified by its upfield shifted H3' proton, is connected to the methylated

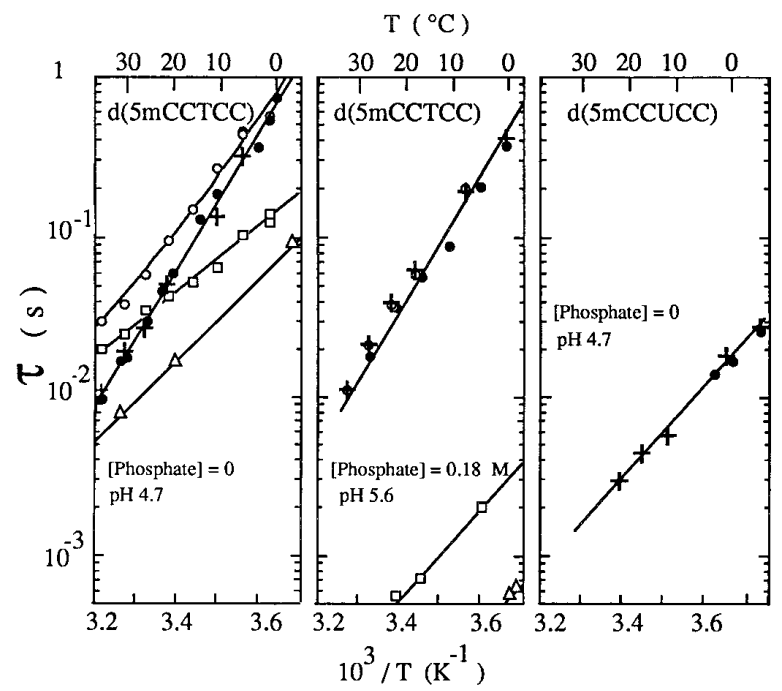

Figure 12. Duplex interconversion times $(\bullet)$ and imino proton exchange times versus temperature in $[\mathrm{d}(5 \mathrm{mCCTCC})] 4$ and in $[\mathrm{d}(5 \mathrm{mCCUCC})] 4: \mathrm{T} 3,(\bigcirc)$; T3* $(\square)$; and $\mathrm{C}^{*}(+)$. Imino proton exchange and interconversion times in $[\mathrm{d}(5 \mathrm{mCCTCC})] 4$ were measured at $\mathrm{pH}$ 4.7 in the absence (left panel) and in the presence (central panel) of a proton exchange catalyst $(0.18 \mathrm{M}$ phosphate) at $\mathrm{pH}$ 5.6. The exchange time of the $\mathrm{T} 3 *$ imino proton is comparable to that of the thymidine monomer $(\triangle)$. The exchange time of the $\mathrm{C} 2 *$ imino proton is identical to the duplex interconversion time. The T3 imino proton does not exchange from the $\{\mathrm{ac}\}$ duplex. In $0.18 \mathrm{M}$ phosphate its exchange time is equal to the duplex interconversion time. In the absence of added proton exchange catalyst, T3 imino proton exchange is controlled either by the duplex interconversion $\left(t<15^{\circ} \mathrm{C}\right)$, or by the exchange rate from $\mathrm{T} 3 *$, the homologous residue on the $\{\mathrm{bd}\}$ duplex $\left(t>30^{\circ} \mathrm{C}\right)$. Right panel: Duplex interconversion time (l) and $\mathrm{C}_{2} *$ imino proton exchange time (+) in $[\mathrm{d}(5 \mathrm{mCCUCC})] 4$.

cytidine by strong $\mathrm{H} 1^{\prime}-\mathrm{H} 1$ ' and $\mathrm{C}_{\mathrm{av}} \mathrm{CH} 3-\mathrm{C} 5_{\mathrm{av}} \mathrm{H} 5$ cross-peaks. $\mathrm{C}_{\mathrm{av}}$ was identified by reciprocal amino-H2'/H2' cross-peaks to $\mathrm{C} 5_{\mathrm{av}}$. The last cytidine spin system was assigned to $\mathrm{C} 2{ }_{\mathrm{av}}$ by the strong $\mathrm{H} 1$ '-H1' cross-peak with $\mathrm{C}_{\mathrm{av}}$. The intercalation topology of the cytidine residues in the motion-averaged structure of $[\mathrm{d}(5 \mathrm{mCCUCC})] 4$ is the same as that determined for $[\mathrm{d}(5 \mathrm{mCCTCC})] 4$.

\section{Proton exchange in $[\mathrm{d}(5 \mathrm{mCCUCC})] 4$}

The proton exchange characteristics are similar to those described above for $[\mathrm{d}(5 \mathrm{mCCTCC})] 4$. At low temperature, the duplex interconversion is slow on the NMR time scale. In this case, exchange of the $\mathrm{C} 2 *$ imino proton is controlled by duplex interconversion as for the $[\mathrm{d}(5 \mathrm{mCCTCC})] 4$ tetramer (Figure 12). At $32^{\circ} \mathrm{C}$, when the duplex interconversion is fast on the NMR time scale, all cytidine imino proton peaks except that of the $\left(\mathrm{C} 4 \cdot \mathrm{C} 4^{+}\right)_{\mathrm{av}}$ pair are broadened by exchange with water. This establishes that the exchange rate of the imino proton of the $\left(\mathrm{C} 4 \cdot \mathrm{C}^{+}\right)_{\text {av }}$ pairs is much slower than the duplex interconversion rate (about $1000 \mathrm{~s}^{-1}$ at 


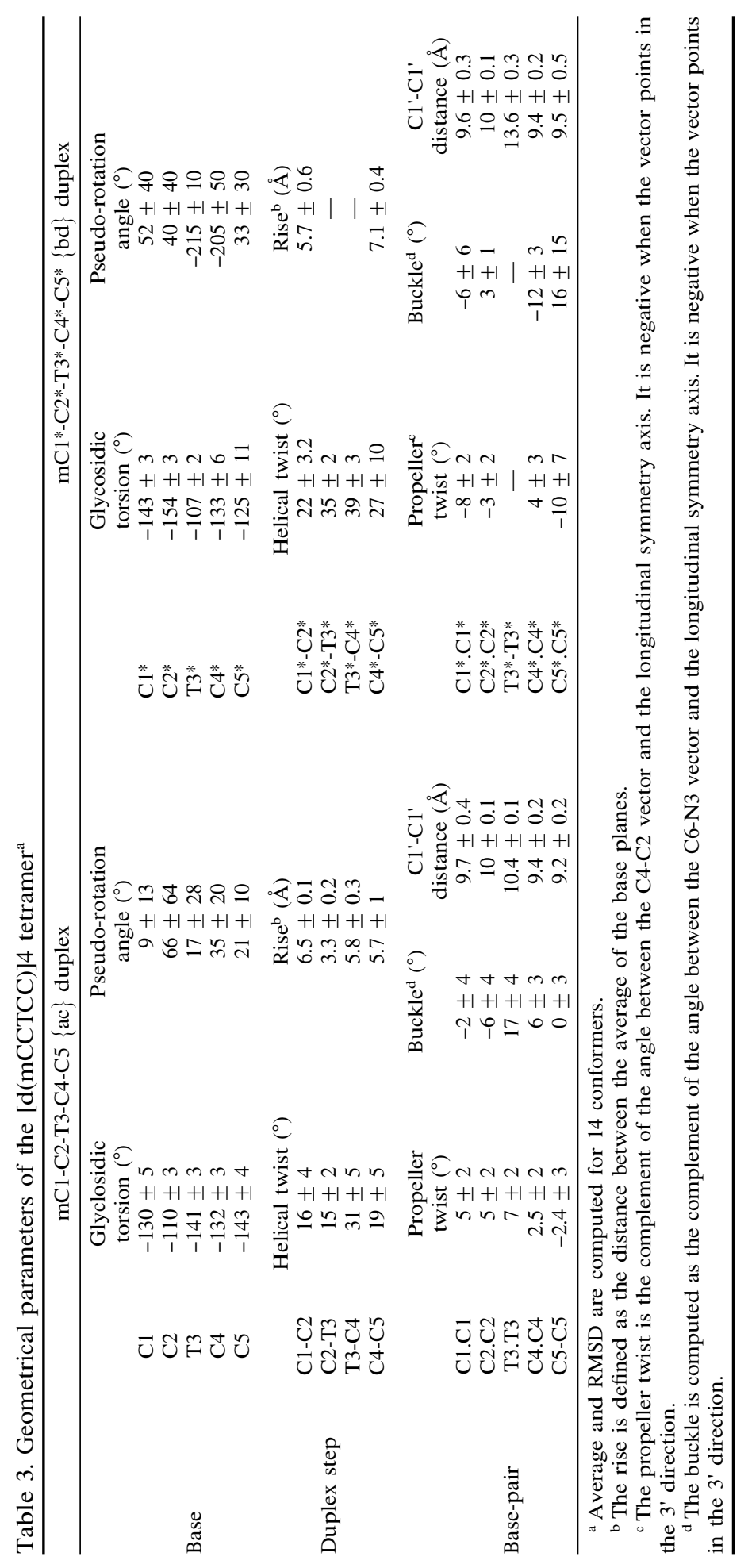


Table 4. Inter-duplex phosphorus-phosphorus distances and base stacking distances in $[\mathrm{d}(\mathrm{mCCTCC})] 4$

\begin{tabular}{|c|c|c|c|c|c|}
\hline \multicolumn{4}{|c|}{ Inter-strand phosphorus-phosphorus distances $(\AA)$} & \multirow{2}{*}{$\frac{\text { Paired bases }}{\mathrm{C} 5^{*} \mathrm{C} 5^{*}-\mathrm{C} 1 . \mathrm{C} 1}$} & \multirow{2}{*}{$\begin{array}{c}\begin{array}{l}\text { Stacking } \\
\text { distances } \\
(\AA)\end{array} \\
3.7 \pm 0.5\end{array}$} \\
\hline Across the wi & grooves & Across the na & W grooves & & \\
\hline $\mathrm{C} 2(\mathrm{P})-\mathrm{C} 5 *(\mathrm{P})$ & $14.9 \pm 0.7$ & $\mathrm{C} 2(\mathrm{P})-\mathrm{C} 5 *(\mathrm{P})$ & $9 \pm 2$ & $\mathrm{C} 1 . \mathrm{C} 1-\mathrm{C} 4 * . \mathrm{C} 4 *$ & $3 \pm 0.4$ \\
\hline $\mathrm{C} 2(\mathrm{P})-\mathrm{C} 4 *(\mathrm{P})$ & $13.4 \pm 2$ & $\mathrm{C} 2(\mathrm{P})-\mathrm{C} 4 *(\mathrm{P})$ & $12.7 \pm 0.9$ & $\mathrm{C} 4 * . \mathrm{C} 4 *-\mathrm{C} 2 . \mathrm{C} 2$ & $3.1 \pm 0.4$ \\
\hline $\mathrm{T} 3(\mathrm{P})-\mathrm{C} 4 *(\mathrm{P})$ & $15.5 \pm 0.6$ & $\mathrm{~T} 3(\mathrm{P})-\mathrm{C} 4 *(\mathrm{P})$ & $12.6 \pm 0.6$ & C2.C2-T3.T3 & $3.1 \pm 0.3$ \\
\hline $\mathrm{T} 3(\mathrm{P})-\mathrm{T} 3 *(\mathrm{P})$ & $13.7 \pm 0.3$ & $\mathrm{~T} 3(\mathrm{P})-\mathrm{T} 3 *(\mathrm{P})$ & $11.1 \pm 0.6$ & $\mathrm{~T} 3 . \mathrm{T} 3-\mathrm{C} 2 * \mathrm{C} 2 *$ & $2.8 \pm 0.3$ \\
\hline $\mathrm{C} 4(\mathrm{P})-\mathrm{T} 3 *(\mathrm{P})$ & $16.1 \pm 0.6$ & $\mathrm{C} 4(\mathrm{P})-\mathrm{T} 3 *(\mathrm{P})$ & $9.4 \pm 1.1$ & $\mathrm{C} 2 * . \mathrm{C} 2 *-\mathrm{C} 4 . \mathrm{C} 4$ & $3 \pm 0.1$ \\
\hline $\mathrm{C} 4(\mathrm{P})-\mathrm{C} 2 *(\mathrm{P})$ & $13.8 \pm 1.2$ & $\mathrm{C} 4(\mathrm{P})-\mathrm{C} 2 *(\mathrm{P})$ & $10.7 \pm 0.7$ & $\mathrm{C} 4 . \mathrm{C} 4-\mathrm{C} 1 * . \mathrm{C} 1 *$ & $2.7 \pm 0.3$ \\
\hline $\mathrm{C} 5(\mathrm{P})-\mathrm{C} 2 *(\mathrm{P})$ & $16 \pm 0.4$ & $\mathrm{C} 5(\mathrm{P})-\mathrm{C} 2 *(\mathrm{P})$ & $9.5 \pm 0.8$ & $\mathrm{C} 1 * . \mathrm{C} 1 *-\mathrm{C} 5 . \mathrm{C} 5$ & $3 \pm 0.4$ \\
\hline
\end{tabular}

$32^{\circ} \mathrm{C}$ ). Due to line overlap, exchange of the U imino proton is not accessible to quantitative measurements.

\section{Discussion}

We have previously reported the structures of the i-motif tetramers formed by d(TCCCCC), (Gehring et al., 1993), d(TCC), d(5mCCT) and d(T5mCC) (Leroy \& Guéron, 1995). Each tetramer structure consists of two intercalating duplexes of parallel strands and the four strands are identical on the NMR time-scale.

The first three oligomers form a single tetrameric structure, which maximizes the degree of intercalation of the duplexes. For (d(T5mCC), two tetramers co-exist. One maximizes intercalations, the second avoids steric hindrance between the cytidine methyl groups by a lesser degree of intercalation. In all the cases, each duplex is made of two identical strands, and the tetramers of four identical strands.

In common with these structures, the tetramer of $\mathrm{d}(5 \mathrm{mCCTCC})$ consists of two intercalated duplexes, each made of two parallel and identical strands. However, the duplexes are not identical: one has its thymidine residues turned inward (designated as $\{\mathrm{ac}\}$ or A) and the other outwards (designated as $\{$ bd or B). The tetramer is an asymmetric assembly $\mathrm{AB}$ and it fluctuates spontaneously between the strictly equivalent $\mathrm{AB}$ and $\mathrm{BA}$ forms. The transition can be followed by the kinetics of the exchange cross-peaks. It is fully concerted: the spectrum shows no indication of other forms, neither AA nor $\mathrm{BB}$, nor of any forms which include a duplex built of non-equivalent strands.

\section{Intercalation of thymidine and tetramer stability}

Duplexes A and B differ essentially by the arrangement of the thymidine residues. In the $\mathrm{A}$ duplex, the NOEs observed between the thymidine residues and the adjacent $\mathrm{C} 2 \cdot \mathrm{C} 2^{+}$and $\mathrm{C} 2 * \cdot \mathrm{C} 2{ }^{*+}$ pairs indicate a symmetrical T3.T3 base-pair. The C1'-C1' distance between the paired thymidine residues $(10.4 \AA)$ is about $1 \AA$ larger than the corresponding distance in $\mathrm{C} \cdot \mathrm{C}^{+}$pairs. This allows the incorporation of the T3.T3 pair within the i-motif without marked distortions of the ribose backbone.
In the B duplex, the $\mathrm{T} 3 *$ residues are symmetrically extruded in the wide grooves.

The similarity of the structures adopted by $\mathrm{d}(5 \mathrm{mCCTCC})$ and by $\mathrm{d}(5 \mathrm{mCCUCC})$ excludes a steric effect in relation with the methyl groups of the thymidine residues, but the difference of the activation energy for the motion of uridine and thymidine residues shows that swinging of the latter is impeded by the methyl group.

One can model an AA tetramer, without any particular van der Waals strain. However, the disposition of the two stacked thymidine pairs which juxtapose negatively charged atoms (N1-02, 02-N1, N3-N3, 04-04) on one hand, and positive carbons (C2-C2) on the other, is electrostatically unfavourable. A BB tetramer can also be modelled but it would have less stacking interactions than an AB.

The comparison of the dissociation constant of $[\mathrm{d}(5 \mathrm{mCCTCC})] 4, K_{\mathrm{d}}=\left(1.1 \times 10^{-4}\right)^{3} \mathrm{M}^{3}$, with that of tetramers formed by a continuous stretch of four cytidine residues such as $[\mathrm{d}(\mathrm{TCCCC})] 4, K_{\mathrm{d}}=\left(10^{-5}\right)^{3}$ (unpublished result) and $[\mathrm{d}(\mathrm{CCCCAA})] 4, K_{\mathrm{d}}=$ $\left(1.2 \times 10^{-5}\right)^{3} \mathrm{M}^{3}$ (Leroy et al., 1994), suggests that incorporation of a $\mathrm{T} \cdot \mathrm{T}$ pair in the i-motif is somewhat destabilizing.

\section{Chemical shift differences between homologous residues}

The chemical shifts in nucleic acids are affected by ring currents and by base protonation. Hbonding also contributes to the chemical shifts of exchangeable protons. The chemical shifts induced by the weak ring current of thymidine (GiessnerPrettre et al., 1976) cannot account for the large shift differences between homologue cytidine residues. The chemical shift differences between the homologous pairs of each duplex are maximal between the $\mathrm{C} 2 \cdot \mathrm{C}^{+}$and $\mathrm{C} 2 * \mathrm{C} 2{ }^{*+}$ pairs, and decrease towards both ends of the tetramer. They reflect the difference of structure between the two duplexes. The NMR peak of the C2 external amino proton has an intriguing upfield shift of 1.34 ppm by comparison to its $\mathrm{C} 2 *$ homologue. By contrast, the internal amino protons of $\mathrm{C} 2$ and $\mathrm{C} 2 *$ are both in the frequency range expected for $\mathrm{H}$-bonded amino protons in $\mathrm{C} \cdot \mathrm{C}^{+}$pairs. In the computed structure of $[\mathrm{d}(5 \mathrm{mCCTCC})] 4$, the thymidine residues $\mathrm{T}^{*}$ are 
Table 5. Imino and amino proton exchange times (seconds) in the [d(5mCCTCC)]4 tetramer

\begin{tabular}{lcccccccccc}
\hline Residue & $\mathrm{C}^{*}$ & $\mathrm{C} 1$ & $\mathrm{C} 4^{*}$ & $\mathrm{C} 2$ & $\mathrm{~T} 3^{*}$ & $\mathrm{~T} 3$ & $\mathrm{C} 2^{*}$ & $\mathrm{C} 4$ & $\mathrm{C} 1^{*}$ & $\mathrm{C} 5$ \\
\hline H3 & $\mathrm{a}$ & $\mathrm{b}$ & 730 & $\mathrm{a}$ & 0.15 & 1 & 0.7 & 730 & $\mathrm{~b}$ & $\mathrm{a}$ \\
H4 & $450 \leqslant^{\mathrm{c}}$ & 5300 & 5300 & 570 & - & - & 570 & 5300 & 5300 & $450 \leqslant \leqslant^{\mathrm{c}}$ \\
H4 & $450 \leqslant \mathrm{ext}$ & $450 \leqslant^{\mathrm{c}}$ & 800 & $\approx 600$ & - & - & 800 & 800 & $450 \leqslant{ }^{\mathrm{c}}$ & $450 \leqslant \mathrm{c}$ \\
\hline
\end{tabular}

${ }^{\text {a }}$ The absence of the imino proton peak indicates exchange times shorter than $5 \mathrm{~ms}$.

${ }^{\mathrm{b}}$ Unresolved proton. Magnetization transfer experiments from water indicate exchange times longer than 0.1 second but too short to be measured in real time experiments: $0.1<\tau_{\text {ex }}<60$ seconds.

${ }^{\mathrm{c}}$ Inaccurate estimation due to insufficient resolution.

symmetrically embedded in the large grooves along the $\mathrm{C} 2 \cdot \mathrm{C} 2^{+}$pair. The external amino proton of $\mathrm{C} 2$ is located $3.5 \AA$ under the N1 atom of T3* in the direction perpendicular to the $\mathrm{T}^{*}$ aromatic ring towards the axis of the helix (Figure 10). In this position, the ring currents of $\mathrm{T} 3 *$ cannot contribute for a chemical shift larger than 0.15 ppm (GiessnerPrettre et al., 1976).

The chemical shifts of $\mathrm{C} 2$ amino protons are unchanged between $\mathrm{pH} 6$ and $\mathrm{pH} 3$, in a $\mathrm{pH}$ range where titration of the N3 position would induce a $1.5 \mathrm{ppm}$ lowfield shift to the amino protons of the cytidine monomer (Razka, 1974). This shows that the anomalous shift is not due to incomplete N3 protonation.

Imino and amino proton chemical shifts are greatly affected by H-bonding to the oxygen or to the nitrogen of the complementary base, and to the oxygen of hydration water. The familiar $11 \mathrm{ppm}$ position of the imino protons of $\mathrm{T}$ and $\mathrm{G}$ monomers corresponds to imino protons $\mathrm{H}$-bonded to water. When dissolved in a solvent such as chloroform, the imino proton of uridine is shifted 2.5 ppm upfield from its position in $\mathrm{H}_{2} \mathrm{O}$ (Guéron et al., 1983). Similarly, the amino protons of the neutral and of the protonated N1-methyl cytidine derivative dissolved in liquid $\mathrm{SO}_{2}$ are shifted upfield by about $2 \mathrm{ppm}$ by reference to their position in $\mathrm{H}_{2} \mathrm{O}$ (Becker et al., 1965). We note that such effects are not observed in dry DMSO solution, due most probably to H-bonding with the polar DMSO oxygen.

In the i-motif, the external amino protons point toward the wide grooves and are usually accessible to water. $\mathrm{C} 2$ external amino proton has the particularity to be buried beneath thymidine T3*. Using the surface generation routine of the Quanta program, we observed that it is the sole external amino proton to be under the surface accessible to a molecule with a radius of $1.3 \AA$. This suggests that the upfield shift of this proton is due to the lack of hydration. According to this interpretation, T3* would form an hydrophobic pocket around the C2 residue, impeding hydration of its external amino proton. The internal amino proton of $\mathrm{C} 2$, which is $\mathrm{H}$-bonded to the oxygen $\mathrm{O} 2$ of the complementary cytidine, is not affected by this effect. This interpretation is consistent with the absence of cross-peaks between water and $\mathrm{C} 2$ amino protons, and with the slow exchange with water of the $\mathrm{C} 2$ external amino proton (Table 5).

\section{Duplex interconversion}

Tetramer dissociation observed by gel filtration chromatography is extremely slow in comparison with duplex interconversion. This shows that the motion of the thymidine residues does not require disruption of the tetramer.

The imino protons of $[\mathrm{d}(5 \mathrm{mCCTCC})] 4$ provide excellent markers to follow the internal motions related to the concerted opening-closing of the thymidine residues. The interpretation of the proton exchange kinetics is particularly straightforward for the imino proton of $\mathrm{C} \cdot \mathrm{C}^{+}$pairs whose exchange time may be identified with the base-pair lifetime (Leroy et al., 1994).

The amino proton spectrum of the $\mathrm{C} 5 \cdot \mathrm{C}^{+}$and $\mathrm{C} 5^{*} \cdot \mathrm{C} 5^{*+}$ pairs shows that these pairs are hemi-protonated, but the absence of imino proton signals on the NMR spectrum at $-7^{\circ} \mathrm{C}$ indicates fast exchange with water. This reflects the fast opening motion of the terminal pairs by reference to the case of terminal Watson-Crick base-pairs (Nonin et al., 1995). The fast exchange rate of the $\mathrm{C} 2 \cdot \mathrm{C}^{+}$pair is also deduced from the lack of imino proton signal for this pair (Figure 3).

There is no indication for $\mathrm{T} 3$ imino proton exchange from the $\{a c\}$ duplex. The absence of effect of ammonia provides an upper limit of $10^{-4}$ for the dissociation constant of the T3.T3 pair. The low $\mathrm{pH}$ conditions required for the i-motif formation impede the study of $\mathrm{T}$ imino proton exchange, and we cannot exclude an opening motion faster that the duplex interconversion for this pair. The local distortions caused by the switch of the thymidine residues entail opening of the $\mathrm{C} 2 * \mathrm{C}^{+}$pair which is found to be synchronized with duplex interconversion. The fast exchange rate of the imino proton of the C2.C2 pair indicates a lifetime shorter than the duplex interconversion time. It may result from unfavourable stacking with the sequentially adjacent T3.T3 pair, or from backbone distortions induced by the open T3* residues.

The exchange rate of $\mathrm{C} 4$ and $\mathrm{C} 4 *$ imino protons is slower than the duplex interconversion rate. According to equation (4) it is equal to the average of the opening rate of $\mathrm{C} 4 \cdot \mathrm{C} 4^{+}$and $\mathrm{C} 4{ }^{*} \mathrm{C} 4^{*+}$ basepair. Hence, the thymidines switch does not require opening of the $\mathrm{C} 4 \cdot \mathrm{C}^{+}$and $\mathrm{C} 4 * \cdot \mathrm{C} 4{ }^{*+}$ pairs whose lifetimes are much longer than the duplex interconversion time. 


\section{[d(5mCCTCC) $] 4$ and other i-motif structures}

The similarity of the $[\mathrm{d}(5 \mathrm{mCCTCC})] 4$ structure with those previously described for other i-motif tetramers, shows that the main features of the i-motif are maintained when a $T \cdot T$ pair is incorporated.

The helical twist at the C2-T3 step $\left(16^{\circ}\right)$ is typical of values found in i-motif structures but the twists at the $\mathrm{T} 3-\mathrm{C} 4, \mathrm{C} 2{ }^{*}-\mathrm{T} 3 *$ and $\mathrm{T} 3{ }^{*}-\mathrm{C} 2 *$ steps are larger. As indicated by the strong NOEs between H3' and H6 protons, all the sugars are N-type except for the open thymidine $\left(\mathrm{T} 3^{*}\right)$ and for the adjacent $\mathrm{C}^{*} *$ residue which are S-type. This is unexpected for $\mathrm{C} 2$ and $\mathrm{T} 3$ which are stacked together, and for which a 2 ' endo sugar-puckering might be expected.

The inter-strand phosphorus-phosphorus distances across the wide grooves are similar to values commonly found in other i-motif structures, but the phosphorus-phosphorus distances across the narrow grooves, in particular those involving the C2-T3*-T3 segment, are larger (Table 3). Examination of the structure shows that the rotation of the $\mathrm{T}^{*}$ sugar backbone towards the major groove may contribute to increase the narrow groove width. The potential $\mathrm{H} 1^{\prime}-\mathrm{H} 1^{\prime} \mathrm{NOE}$ expected between couples 5mC1-C5*, C2-C4* and C2-T3* (see Figure 8) falls in the strong non-resolved $\beta$ cross-peak (Figure 2). The absence of distance constraints across this section of the narrow groove may result in an over-evaluation of the groove width.

Each hemi-protonated duplex of $[\mathrm{d}(5 \mathrm{mCCTCC})] 4$ is symmetrical on the NMR time-scale. Common to all solution structures, this feature contrasts with the duplex asymmetry observed in the crystal structures of i-motif tetramers (Chen et al., 1994; Kang et al., 1995; Berger et al., 1995). In the case of $\mathrm{d}[\mathrm{d}(\mathrm{CCCT})] 4$, the solution (J.-L. Leroy, unpublished result) and crystal structures (Kang et al., 1994) are available. In the crystal, the tetramer is formed by the intercalation of two identical duplexes, each of which is non-symmetrical, whereas in solution the duplexes are symmetrical even at very low temperature: $-30^{\circ} \mathrm{C}$ for a spectrum obtained in $33 \%$ deuterated methanol $67 \% \mathrm{H}_{2} \mathrm{O}$.

Different phenomena can contribute to this difference. The NMR structure may correspond to fast exchange in solution between different strand structures. The crystal structure may be due in part or entirely to crystal packing.

The asymmetric $[\mathrm{d}(5 \mathrm{mCCTCC})] 4$ tetramer is an example of an association of identical units in which the equivalence is lost. It is a case of broken symmetry in a biological macromolecular assembly, the first in which the structure and switching kinetics are fully characterized. The switching properties of the asymmetrical "AB" tetramer could be investigated in other sequences derived from $5 \mathrm{mCCTCC}$. The number of thymidine or of cytidine residues may be increased.

\section{Materials and Methods}

\section{Oligomer preparation and NMR samples}

The oligomers were synthesized and purified according to procedures already described (Leroy \& Guéron, 1995). The strand concentration of the NMR samples, $6 \mathrm{mM}$ for $\mathrm{d}(5 \mathrm{mCCUCC})$ and $8 \mathrm{mM}$ for $\mathrm{d}(5 \mathrm{mCCTCC})$, was determined from the absorbance measured at neutral $\mathrm{pH}$ using the $A_{260}$ value of $39,250 \mathrm{M}^{-1}$ computed according to a nearest neighbour model (Cantor \& Warshaw, 1970).

\section{Gel filtration chromatography}

The oligomer stoichiometry was determined from the concentration dependence of the multimer-monomer equilibrium, as measured by high pressure chromatography on a Synchropack GPC 100 Gel filtration column. The column was calibrated with mononucleosides ( $\mathrm{C}$ and T), with single-stranded oligomers, with DNA duplexes, and with oligo $(\mathrm{C})$ tetramers such as $[\mathrm{d}(\mathrm{TCCCCC})] 4$, $[\mathrm{d}(\mathrm{CCCCAA})] 4$ and $[\mathrm{d}(\mathrm{TTCCCCCCCCTT})] 4$. The samples injected in the chromatography column were prepared by dilution of small aliquots obtained from the NMR samples into a $0.3 \mathrm{M} \mathrm{NaCl}, 20 \mathrm{mM}$ acetate buffer $(\mathrm{pH}$ 4.7). They were incubated four days at room temperature in order to reach the monomer-tetramer equilibrium. The sample were eluted in less eight minutes (flow rate $0.4 \mathrm{ml} / \mathrm{min}$ ).

\section{NMR methods}

NMR experiments were performed on a home-built $360 \mathrm{MHz}$ spectrometer and on a Bruker AMX600 spectrometer. The "jump and return" sequence with maximum sensitivity at $13.5 \mathrm{ppm}$ was used for water suppression (Plateau \& Guéron, 1982).

All NOESY experiments used $90^{\circ}$ pulses for preparation, mixing and detection.

Pure exchange spectra were obtained using a mixed "NOESY-ROESY" sequence designed to compensate the effects of longitudinal and transverse relaxation in order to suppress the cross-relaxation. This is achieved by forcing the magnetization to spend twice as much time along the main field axis than in the perpendicular direction. The sequence was derived from that described by Fejzo et al. (1991), by addition of $z$-gradient pulses before and after the NOESY-ROESY loop for the suppression of extraneous transverse magnetization. The elimination of the dipolar cross-peaks was checked by the absence of the cytidine intra-residue H5-H6 NOE cross-peaks (Figure 4).

NOESY and NOESY-ROESY experiments in $\mathrm{H}_{2} \mathrm{O}$ were read with the JR sequence. The spectral width was $7.2 \mathrm{kHz}$, the acquisition time 0.23 second, and the repetition rate one second. The $t_{1}$ delay (240 increments) was incremented from $2 \mu$ s to $60 \mathrm{~ms}$.

$2 \mathrm{D}$ experiments in ${ }^{2} \mathrm{H}_{2} \mathrm{O}$ were recorded with a spectral width of $3 \mathrm{kHz}$ and an acquisition time of 0.34 second. The repetition rate was two seconds. The residual $\mathrm{H}^{2} \mathrm{HO}$ signal was generally not saturated in order to avoid saturation of the $\mathrm{H} 3$ ' protons. The $t_{1}$ delay was incremented from $2 \mu$ s to $84 \mathrm{~ms}$ ( 256 increments). TOCSY experiments used ten MLEV-17 repetitions (total time $15 \mathrm{~ms}$ ) without trim pulses (Bax et al., 1985).

The 2D data were processed with Felix 1.1 (courtesy of Hare Research). Apodization in both dimensions 
included exponential broadening $\left(1 \mathrm{~Hz}\right.$ in ${ }^{2} \mathrm{H}_{2} \mathrm{O}, 3 \mathrm{~Hz}$ in $\mathrm{H}_{2} \mathrm{O}$ ), a sine-bell with a phase shift of either $40^{\circ}$ for peak assignment, or $60^{\circ}$ for measurement of NOESY crosspeak volumes and for observation of exchange crosspeaks near the diagonal, and with a Felix skew factor of 0.8 . The remaining water signal was reduced on $1 \mathrm{D}$ and 2D experiments by post-acquisitional processing. 1D spectra were corrected for the frequency response to the JR excitation (Guéron et al., 1991).

\section{Rate of duplex interconversion}

The rate of duplex interconversion was determined in ${ }^{2} \mathrm{H}_{2} \mathrm{O}$ solution from the rate of magnetization transfer between the $\mathrm{H} 6$ protons of the thymidine residues of each duplex. Let $\{\mathrm{ac}\}$ and $\{\mathrm{bd}\}$ be the duplexes, and $\mathrm{T} 3$ and T3* their respective thymidine residues. The magnetization of T3 H6 was selectively saturated using a $90^{\circ}$ DANTE pulse followed by a $1 \mathrm{~ms} z$-gradient pulse. The peak was saturated by a succession of DANTE pulses followed by a $0.5 \mathrm{~ms} Z$-gradient pulse. The longitudinal magnetization, $M_{z}(t)$, of $3^{*} \mathrm{H} 6$ was measured as a function of the time during which T3 H6 was maintained saturated. According to Forsèn \& Hoffman (1963):

$$
M_{\mathrm{z}}(t)=M_{0}\left[\left(T_{1 \mathrm{~d}} / \tau_{\mathrm{d}}\right) \exp \left(-t / T_{1 \mathrm{~d}}\right)+\left(T_{\mathrm{ld}} / T_{1}\right)\right]
$$

where $\tau_{\mathrm{d}}$ is the duplex interconversion time, and $T_{1}$ is the longitudinal relaxation time of T3* H6. $M_{0}$ is the initial magnetization of $\mathrm{T}^{*} \mathrm{H} 6$, and $T_{\mathrm{ld}}=\left(1 / \tau_{\mathrm{d}}+1 / T_{1}\right)^{-1} . T_{1}$ was determined in a separate set of inversion-recovery experiments.

\section{Imino proton exchange}

Exchange of the imino proton in a base-pair requires disruption of the pair, followed by proton transfer to an acceptor such as $\mathrm{NH}_{3}$ or phosphate acting as catalyst. Imino proton exchange from the open pair is also catalysed by the cyclic nitrogen of the paired nucleotide (A N1 in A.T pairs, $\mathrm{C} \mathrm{N} 3$ in $\mathrm{C} \cdot \mathrm{C}^{+}$pairs) which acts as an intrinsic catalyst in a concerted transfer involving a water molecule (Guéron et al., 1987). The exchange time, $\tau_{\mathrm{ex}}$, is given by:

$$
\tau_{\mathrm{ex}}=\tau_{0}\left[1+1 /\left(K_{\mathrm{diss}} \times k_{\mathrm{ex}, \text { acc open }}\right)\right]
$$

where $\tau_{0}$ is the base-pair lifetime, $K_{\text {diss }}$ the dissociation constant, and $k_{\text {ex,acc open, the rate of transfer to the proton }}$ acceptor from the open pair.

In the case of a C.C. $\mathrm{C}^{+}$base-pair, the intrinsic catalysis is so efficient that the imino proton exchanges with water at each opening event, so that the exchange time is equal to the base-pair lifetime (Leroy et al., 1994).

\section{Imino proton exchange in the case of two exchanging structures}

The exchange rate of several imino protons of the [d(5mCCTCC $)] 4$ tetramer depends on the rate of duplex interconversion. Let $\mathrm{N}$ be a residue of the $\{\mathrm{ac}\}$ duplex, and $\mathbf{N}^{*}$ the corresponding residue in the $\{\mathrm{bd}\}$ duplex.

$$
\begin{aligned}
& k_{\mathrm{exN}} \quad k_{1} \quad k_{\mathrm{exN}}{ }^{*} \\
& \text { exchange } \leftarrow\{\text { ac }\} \text { duplex } \leftrightarrow\{\text { bd }\} \text { duplex } \rightarrow \text { exchange } \\
& \text { residue } \mathrm{N} \text { residue } \mathrm{N}^{*}
\end{aligned}
$$

The expression of imino proton exchange is simple in three extreme cases.

(1) When the duplex interconversion rate $K_{1}$ is slower than both imino proton exchange rates, $\left(k_{\mathrm{exN}}, k_{\mathrm{exN}} *>k_{1}\right)$, exchange occurs independently from $\mathrm{N}$ and from $\mathrm{N}^{*}$ with the rate $k_{\mathrm{exN}}$ and $k_{\mathrm{exN}}{ }^{*}$.

(2) When the duplex interconversion rate is faster than the exchange rate of the imino proton of one species $\left(k_{\mathrm{exN}} *>k_{1}>k_{\mathrm{exN}}\right.$ for instance), the measured exchange rate of the slow exchanging imino proton, $k_{\operatorname{mes}}$, depends on the interconversion rate and on the exchange rate from $\mathrm{N}^{*}$ according to:

$$
k_{\mathrm{mesN}}=k_{1} \quad k_{\mathrm{exN}} * /\left(k_{1}+k_{\mathrm{exN}} *\right)
$$

whereas the exchange rate of the fast exchange rate is not affected.

(3) When the interconversion rate is faster than both imino proton exchange rates $\left(k_{1}>k_{\mathrm{exN}}{ }^{*}, k_{\mathrm{exN}}\right)$, the imino protons exchange at the same rate:

$$
k_{\mathrm{mesN}}=k_{\mathrm{mesN}}=\left(k_{\mathrm{exN}}{ }^{*}+k_{\mathrm{exN}}\right) / 2
$$

The rates of proton exchange were measured as described previously (Guéron \& Leroy, 1996).

\section{Structure determination}

\section{NMR determinants of the i-motif}

In the intercalated duplexes, the large distances between sequentially adjacent residues result in the quasi-absence of sequential NOE connectivities at short mixing time. The intercalation topology of the i-motif is read off the patterns of $\mathrm{H} 1$ '-H1' cross-peaks which connect the stacked residues across the narrow grooves (Gehring et al., 1993), and of the amino-H2'/H2" cross-peaks connecting across the wide grooves the nucleotides stacked via contacting 3'-faces. Stacked $\mathrm{C}^{\prime} \mathrm{C}^{+}$ pairs are also connected by strong $\mathrm{H} 5$-amino proton cross-peaks (Leroy \& Guéron, 1995). The intercalation stretches the sugar-phosphate backbones, leading to $\mathrm{N}$-type puckers and strong intra-residue H3'-H6 crosspeaks.

\section{NOESY cross-peaks and distance restraints}

The structure of $[\mathrm{d}(5 \mathrm{mCCTCC})] 4$ was determined on the basis of the inter-proton distances obtained from the build-up of NOE cross-peaks measured at mixing times of $40,60,85,110,135,150$ and $230 \mathrm{~ms}$ in $\mathrm{H}_{2} \mathrm{O}$ at $-7^{\circ} \mathrm{C}$, and of $35,70,90,120$ and $250 \mathrm{~ms}$ in ${ }^{2} \mathrm{H}_{2} \mathrm{O}$ at $-5^{\circ} \mathrm{C}$. We distinguished the cross-peaks due to cross-relaxation from those due to chemical exchange using pure chemical exchange spectra.

The NOESY cross-peak volumes were measured manually as the product of the number of contour plots by the cross-peak section at half-height. Inter-proton distances were scaled using the intra-residue H5-H6 cross-peak of $\mathrm{C} 4, \mathrm{C} 4^{*}, \mathrm{C} 5, \mathrm{C}^{*}$ and $\mathrm{C} 2^{*}$ and the corresponding inter-residue distance of $2.45 \AA$.

Distances involving a methyl group were scaled by reference to the H6-CH3 pseudo-atom distance of $2.9 \AA$.

The distances were sorted into three categories corresponding to lower and upper bounds of 1.8 to 2.9 , 1.8 to 3.7 and 2.9 to $4.2 \AA$. In some cases, the absence of NOE or the observation of weak cross-peaks at long mixing time was converted into repulsive restraints with a lower bond of $4.2 \AA$. For cross-peaks involving geminal protons, we used the distance corresponding to the strongest cross-peak as a restraint. The distances derived from the other cross-peaks were considered as lower 
bonds. The distances involving methyl protons or C.C $\mathrm{C}^{+}$ imino protons were loosened by $\pm 0.5 \AA$.

Due to insufficient spectral resolution, several crosspeaks, in particular many of those which connect $\mathrm{C}^{*}$ to $5 \mathrm{mC} 1$ at one end of the tetramer, and $\mathrm{C} 5$ to $5 \mathrm{mC} 1 *$ at the other end, could not be translated into distance restraints. In such cases, we verified on the final computed structure that at least one of the corresponding inter-proton distances can account for the intensity of these cross-peaks.

The sugar conformation and the glycosidic torsion angles were constrained by distances derived from intra-residue $\mathrm{H} 3{ }^{\prime}-\mathrm{H} 6, \mathrm{H} 1^{\prime}-\mathrm{H} 6$, and $\mathrm{H} 3^{\prime}-\mathrm{H} 2^{\prime} / \mathrm{H} 2 "$ NOE cross-peaks. The structures computed with and without the intra-residue restraints show the same intercalation topology.

\section{Base-pairing restraints}

Based-paired strands were designated $\{a\}$ and $\{c\}$ for one duplex, and $\{b\}$ and $\{d\}$ for the other. The chemical shifts and the exchange properties of imino and amino protons indicated the base-pairing of the cytidine residues. The C. $\mathrm{C}^{+}$pairs were defined by the $\mathrm{O} 2-\mathrm{N} 4$ and N3-N3 distances which were both set to $2.75( \pm 0.1) \AA$. No base-pairing was imposed for the thymidine residues. We did not impose planarity of the base-pairs.

\section{Strand equivalence and symmetry restraints}

The NMR spectra of $[\mathrm{d}(5 \mathrm{mCCTCC})] 4$ show the intercalation of two distinct symmetrical duplexes. The strategy used to overcome the ambiguities resulting from the duplex symmetry is derived from that previously used to solve the structure formed by four identical d(TCC) strands (Leroy \& Guéron, 1995). The modelling started with four strands $(\{a\},\{b\},\{c\}$, and $\{d\})$ in arbitrary extended conformations with ideal geometry. Each parallel duplex, $\{\mathrm{ac}\}$ and $\{\mathrm{bd}\}$, was defined by the base-pairing distance restraints declared between the equivalent cytidine. In order to enforce the identity of the base-paired strands, several intra-residue distances (O2-O3', N4/O4-C4', N1-C5', and N3-C2') were declared identical (within $0.1 \AA$ ) for each base-paired residue. The equivalence of the $\{a\}-\{b\}$ and $\{c\}-\{d\}$ inter-strand relations was enforced by six inter-strand segments, which were defined between a selected set of atoms (N3, $\mathrm{C} 4, \mathrm{C} 5, \mathrm{~N} 1, \mathrm{O} 4{ }^{\prime}, \mathrm{O} 3$ ') of the residues of strand $\{\mathrm{a}\}$, and the same set of atoms of the corresponding residues of strand $\{b\}$. These segments were declared equivalent (within $\pm 0.1 \AA$ ) to the equivalent segments defined between strands $\{c\}$ and $\{d\}$. Similarly the corresponding segments defined between strands $\{a\}$ and $\{d\}$, and between strands $\{c\}$ and $\{b\}$ were declared equivalent. Using this procedure we obtained an RMSD of about $0.1 \AA$ between the equivalent strands of each computed conformer, a value much smaller than the RMSD between two computed conformers.

Due to the symmetry of the duplexes, the strand appartenance of the NOE-connected protons is ambiguous. To solve these ambiguities, a preliminary model was built using only the distance restraints derived from the characteristic $\mathrm{H} 1^{\prime}-\mathrm{H} 1^{\prime}$ and amino- $\mathrm{H} 2{ }^{\prime} / \mathrm{H} 2 "$ cross-peaks. By reference to the conventions used in the structural study of $[\mathrm{d}(\mathrm{TCC})] 4$ and $[\mathrm{d}(5 \mathrm{mCCT})] 4$, (Leroy \& Guéron, 1995), we designate $\{a\}-\{b\}$ the couples of strands connected by amino-H2'/H2" NOE cross-peaks, and $\{c\}-\{d\}$ the couple of strands connected by the short
H1'-H1' distances. Using this preliminary model, we could assign all the other inter-duplex connectivities to either the $\{a\}-\{b\}$ or to the $\{a\}-\{d\}$ couples of strands. Similarly, the intra-duplex NOE cross-peaks could be assigned either to intra-strand distance connectivities or to distance connectivities between equivalent base-paired strands.

The NMR spectrum implies an identical environment for the two strands of a duplex. To this end, identical sets of distance restraints were declared between the couples of strands $\{a\}-\{d\}$, and $\{c\}-\{b\}$, and between the couples $\{a\}-\{b\}$ and $\{c\}-\{d\}$. Identical sets of intra-strand distances were declared in strands $\{a\}$ and $\{c\}$, and in strands $\{b\}$ and $\{d\}$.

\section{Distance restrained molecular dynamics}

The structures were computed using the simulated annealing method (Brünger, 1990) of the X-PLOR program. Potential energy terms related to electrostatics and "empirical dihedral" were omitted. The force constant expressing distance restraints was set to $50 \mathrm{kcal} \mathrm{mol}^{-1} \AA^{-2}$. The force constant related to H-bonding restraints was set to $500 \mathrm{kcal} \mathrm{mol}^{-1} \AA^{-2}$. The standard harmonic potential for covalent geometry was used. The simulated annealing proceeded as follows. In a preliminary phase, the energy of the starting structure was minimized by five Powell cycles. The molecular dynamics computation was run for 2000 steps of 2 ps, with an initial velocity corresponding to $2000 \mathrm{~K}$. H-bonding energy was introduced during the cooling procedure to $300 \mathrm{~K}$ in steps of $25 \mathrm{~K}$, each step being followed by a 0.1 ps dynamics computation. Lastly, the energy was minimized by 400 Powell cycles. The computation was repeated to yield 24 conformers.

Thirteen conformers were selected for their low NOESY-related energy. The RMSD were determined by pairwise comparison of the conformers aligned on their C1' positions.

\section{Coordinates deposition}

The coordinates of the lowest NOESY-related energy conformer $[\mathrm{d}(5 \mathrm{mCCTCC})] 4$ have been submitted to the Protein Data Bank, Chemistry Department, Brookhaven National Laboratory, Upton, NY 11973, USA, and are available from the authors on request until released.

\section{Acknowledgements}

We thank M. Guéron for stimulating discussions and help in the preparation of the manuscript. We thank M. Leblond for synthesis and purification of DNA. X. Han is acknowledged for assistance with gel filtration chromatography. This work was supported by grant 6520/6 July 1994 from The Association pour la Recherche contre le Cancer.

\section{References}

Bax, A. \& Davis, D. G. (1985). MLEV-17 based two-dimensional homonuclear magnetization transfer spectroscopy. J. Magn. Reson. 65, 355-360.

Becker, E. D., Todd Miles, H. \& Bradley, R. B. (1965). Nuclear magnetic resonance studies of methyl 
derivatives of cytosine. J. Am. Chem. Soc. 87, 5575-5582.

Berger, I., Kang, C., Fredian, A., Ratliff, R., Moyziz, R. \& Rich, A. (1995). Extension of the four-stranded intercalated cytosine motif by adenine-adenine base-pairing in the crystal structure of d(CCCAAT). Struct. Biol. 2, 416-425.

Brünger, A. T. (1990). X-PLOR Version 3.1, a system for $\mathrm{X}$-ray crystallography.

Cantor, C. R. \& Warshaw, M. M. (1970). Oligonucleotide interactions. III. Circular dichroism studies of the conformation of deoxyoligonucleotides. Biopolymers, 9, 1059-1077.

Chen, L., Cai, L., Zhang, X. \& Rich, A. (1994). Crystal structure of a four-stranded intercalated DNA: d(C4). Biochemistry, 33, 13540-12546.

Fejzo, J., Westler, W. M., Macura, S. \& Markley, J. L. (1991). Strategies for eliminating unwanted crossrelaxation and coherence-transfer effects from twodimensional chemical-exchange spectra. J. Magn. Reson. 92, 20-29.

Forsèn, S. \& Hoffman, R. A. (1963). Study of moderately rapid chemical exchange reaction by means of nuclear magnetic double resonance. J. Chem. Phys. 39, 2892-2901.

Gehring, K., Leroy, J.-L. \& Guéron, M. (1993). A tetrameric DNA structure with protonated cytidinecytidine base pairs. Nature, 363, 561-565.

Giessner-Prettre, C., Pullman, B., Borer, P. N., Kan, L.-S. \& Ts'o P. O. P. (1976). Ring-current effects in the NMR of nucleic acids. Biopolymers, 15, 2277-2286.

Guéron, M. \& Leroy, J.-L. (1996). Nucleic acid dynamics. Methods Enzymol. 261, 383-413.

Guéron, M., Leroy, J.-L. \& Griffey, R. H. (1983). Proton nuclear magnetic relaxation of ${ }^{15} \mathrm{~N}$-labelled nucleic acids via dipolar coupling and chemical shift anisotropy. J. Am. Chem. Soc. 105, 7262-7266.

Guéron, M., Kochoyan, M. \& Leroy, J.-L. (1987). A single mode of DNA base-pair opening drives imino proton exchange. Nature, 382, 89-92.

Guéron, M., Charretier, E., Hagerhorst, J., Kochoyan, M., Leroy, J.-L. \& Moraillon, A. (1989). In Biological Structure, Dynamics, Interactions \& Expression; Proceedings of the Sixth Conversation in Biomolecular Stereodynamics (Sarma, R. H. \& Sarma, M. H., eds), vol. 2, pp. 113-137, Adenine Press, New York.

Guéron, M., Plateau, P. \& Decorps, M. (1991). Solvent signal suppression in NMR. Prog. NMR Spectrosc. 23, 135-209.
Inman, R. B. (1964). Transition of DNA homopolymers. J. Mol. Biol. 9, 624-637.

Kang, C., Berger, I., Lockshin, C., Ratliff, R., Moyzis, R. \& Rich, A. (1984). Crystal structure of intercalated four-stranded d(C3T) at $1.4 \AA$ A. Proc. Natl Acad. Sci. USA, 91, 11636-11640.

Kang, C., Berger, I., Lockshin, C., Ratliff, R., Moyzis, R. \& Rich, A. (1995). Stable loop in the crystal structure of the intercalated four-stranded cytosine-rich metazoan telomer. Proc. Natl Acad. Sci. USA, 92, 3874-3878.

Langridge, R. \& Rich, A. (1963). Molecular structure of helical polycytidylic acid. Nature, 198, 725-728.

Leroy, J.-L. \& Guéron, M. (1995). Solution structure of the i-motif tetramers of $\mathrm{d}(\mathrm{TCC}), \mathrm{d}(5 \mathrm{methylCCT})$ and d(T5methylCC): novel NOE connection between amino protons and sugar protons. Structure, 3, $101-120$.

Leroy, J.-L., Gehring, K., Kettani, A. \& Guéron, M. (1993). Acid multimers of oligo-cytidine strands: stoichiometry, base-pair characterization and proton exchange properties. Biochemistry, 3, 60196031.

Leroy, J.-L., Guéron, M., Mergny, J.-L. \& Helène, C. (1994). Intra-molecular folding of a fragment of the cytosine-rich strand of telomeric DNA into an i-motif. Nucl. Acids Res. 22, 1600-1606.

Mergny, J.-L., Lacroix, L., Han, X., Leroy, J.-L. \& Helène, C. (1995). Intra-molecular folding of pyrimidine oligodeoxynucleotides into an i-DNA motif. J. Am. Chem. Soc. 117, 8887-8898.

Nilges, M. (1993). A Calculation strategy for the structure determination of symmetric dimers by NMR. Proteins: Struct. Funct. Genet. 17, 297-309.

Nonin, S., Leroy, J.-L. \& Guéron, M. (1995). Terminal base pair of oligodeoxynucleotides: imino proton exchange and fraying. Biochemistry, 34, 1065210659.

Plateau, P. \& Guéron, M. (1982). Exchangeable proton NMR without base-line distortion, using strong pulse sequences. J. Am. Chem. Soc. 104, 7310-7311.

Razka, M. (1974). Mononucleotides in aqueous solution: proton magnetic resonance studies of amino groups. Biochemistry, 13, 4616-4622.

Rohozinski, J., Hancock, J. M. \& Keniry, M. A. (1994). Oligocytodine regions contained in DNA hairpin loops interact via a four-stranded, parallel structure similar to the i-motif. Nucl. Acids Res. 22, 4653-4659. 